Atrkivoc

Archive for

Organic Chemistry
The Free Internet Journal

for Organic Chemistry
Paper

Arkivoc 2020, part v, 1-16

\title{
Pyrimidine-2,4-diamines as antiplasmodial antifolates
}

Tswene D. Seanego, ${ }^{a}$ Hanna F. Klein, ${ }^{a}$ Natasha C. Jansen van Vuuren,, ${ }^{b, c}$ Robyn L. van Zyl, ${ }^{b, c}$ and Amanda L. Rousseau*a,c

${ }^{a}$ Molecular Sciences Institute, School of Chemistry, University of the Witwatersrand, Private Bag 3, PO WITS, 2050, South Africa

${ }^{b}$ Pharmacology Division, Department of Pharmacy and Pharmacology, Faculty of Health Sciences, University of the Witwatersrand, 7 York Road, Parktown 2193, South Africa

${ }^{c}$ WITS Research Institute for Malaria (WRIM), University of the Witwatersrand, 7 York Road, Parktown 2193, South Africa

Email: Amanda.Rousseau@wits.ac.za

Received 07-27-2020

Accepted 08-19-2020

Published on line 09-09-2020

\section{Abstract}

Two series of substituted pyrimidine-2,4-diamines with a flexible side chain at either the 5- or 6-position of the pyrimdine ring were designed as potential inhibitors of $P$. falciparum dihydrofolate reductase (DHFR). The compounds were synthesised and evaluated for antiplasmodial activity in vitro against a cycloguanil-resistant strain of the $P$. falciparum parasite. 5-(3-(3,5-Dichlorophenoxy)propyl)-6-phenylpyrimidine-2,4-diamine was identified as the most promising compound ( $\left.\mathrm{IC}_{50} 0.86 \mu \mathrm{M}\right)$. In general, pyrimidine-2,4-diamines substituted at the 5 -position of the pyrimidine ring showed better antiplasmodial activity $\left(\mathrm{IC}_{50} 0.86-26.55 \mu \mathrm{M}\right)$ than those bearing a modified side chain at the 6-position of the pyrimidine ring ( $\left(\mathrm{C}_{50} 4.46-83.45 \mu \mathrm{M}\right)$.

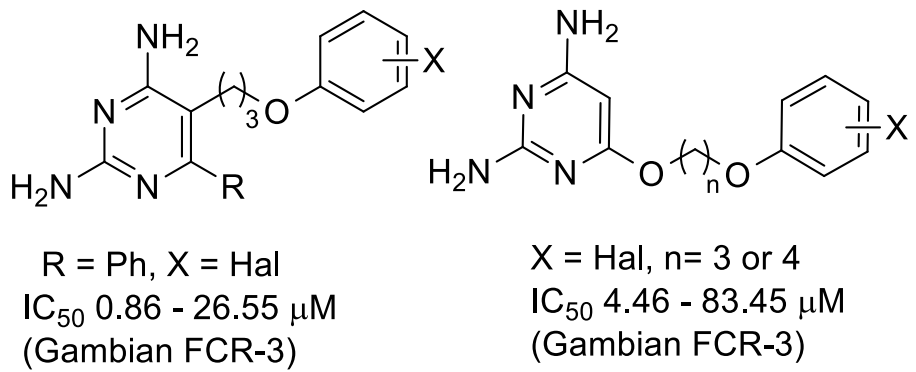

Keywords: Pyrimidine-2,4-diamines, antifolates, dihydrofolate reductase, antiplasmodial activity 


\section{Introduction}

In 2018, approximately half of the world's population was at risk of contracting malaria, a disease caused by parasitic protozoa of the genus Plasmodium. ${ }^{1}$ According to the most recent World Malaria Report, $93 \%$ of the estimated 228 million malaria cases and $94 \%$ of the 405,000 deaths worldwide in 2018 were caused by Plasmodium falciparum, one of the Plasmodium species responsible for causing malaria in humans which is prevalent in sub-Saharan Africa. While malaria-prevention tools such as indoor residual spraying (IRS) of insecticides, the use of insecticide-treated nets (ITNs), and intermittent preventative therapy in pregnancy (IPTp) have played a major role in decreasing malaria incidence and mortality over the last five years, the WHO estimates that $43 \%$ of people at risk of contracting malaria in sub-Saharan Africa do not have access to these preventative tools. ${ }^{1}$ Furthermore, although there has been a significant decline in the number of malaria fatalities over the last 15 years, the rate of decline has decreased, with mortality rates remaining at similar levels since 2014. ${ }^{1}$

Folates are cellular cofactors that play an essential role in the life cycle of the malaria parasite. ${ }^{2}$ Antimalarial antifolates target two key parasitic enzymes, dihydropteroate synthase (DHPS) and dihydrofolate reductase, which, in the parasite, is a bifunctional dimer with thymidylate synthase (DHFR-TS). These enzymes are responsible for maintaining adequate cellular levels of folate derivatives either via a folate salvage pathway or a de novo synthetic pathway. ${ }^{3}$ The combination therapy of sulfadoxine-pyrimethamine, used in IPT both in pregnancy and in infants under the age of 5 years, targets these enzymes in the parasite, with pyrimethamine (1) targeting DHFR (Figure 1). Unfortunately, resistance to pyrimethamine and other anti-DHFR drugs, such as cycloguanil (2), is widespread and has limited their clinical usefulness ${ }^{4-5}$ Point mutations in the active site of the DHFR domains of DHFR-TS have been shown to be responsible for the development of resistance to these antifolates, which contain a rigid biaryl axis. ${ }^{6}$ Related compounds with inherent flexibility, such as WR99210 (3) and P65 (4) (Figure 1), however, have been shown to maintain a high binding affinity to all mutant forms of $P$. falciparum DHFR. ${ }^{7}$ These compounds contain a flexible linker between the two rings, which enables the compounds to avoid unfavourable contacts with mutant amino acid residues in the DHFR active site.

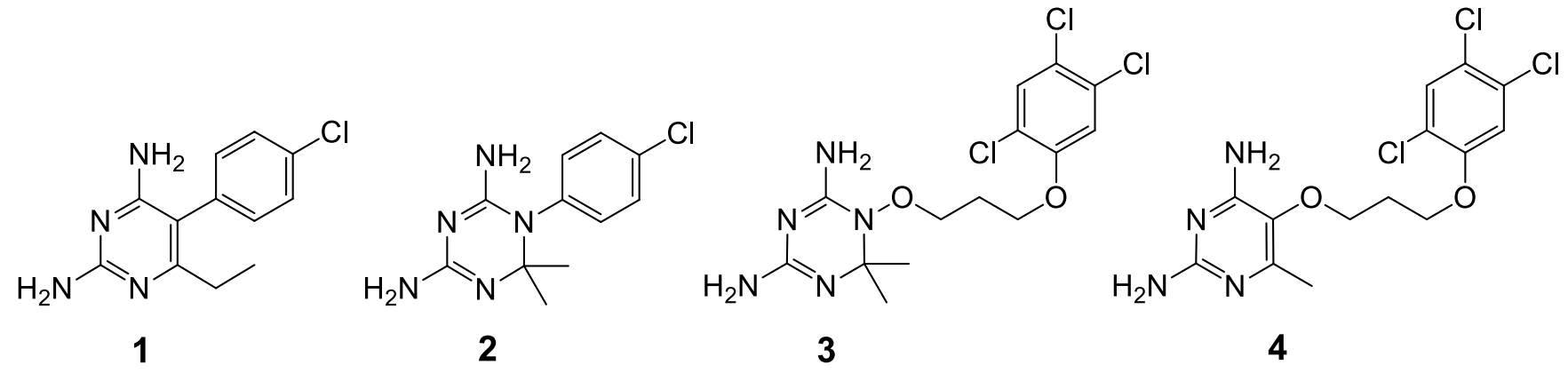

Figure 1. Known antifolates pyrimethamine (1), cycloguanil (2), WR99210 (3) and P65 (4).

Based on these findings, we reported the synthesis of a series of novel, flexible analogues of cycloguanil bearing a 4-atom linker between the two rings (see general structure (5), Figure 2), with in vitro antimalarial activity in the low nanomolar range against both drug-sensitive and drug-resistant 
strains of $P$. falciparum. ${ }^{8}$ The compounds were shown to inhibit parasitic DHFR, and were not cytotoxic. Despite the promising biological activity of these compounds; however, they were isolated as racemic mixtures in generally low yields. Furthermore, the synthesis proved challenging ${ }^{9}$ and could not readily be adapted for asymmetric synthesis. Herein, we report the synthesis of pyrimidine analogues of general structure (6) of our dihydrotriazine series (5), and their biological activity in a whole cell $P$. falciparum assay. We also embarked on the synthesis of analogues of $\mathrm{P} 65$, of general structure (7), bearing a longer side chain moved to the 6-position of the pyrimidine ring in order to assess the effect of this on biological activity in vitro.
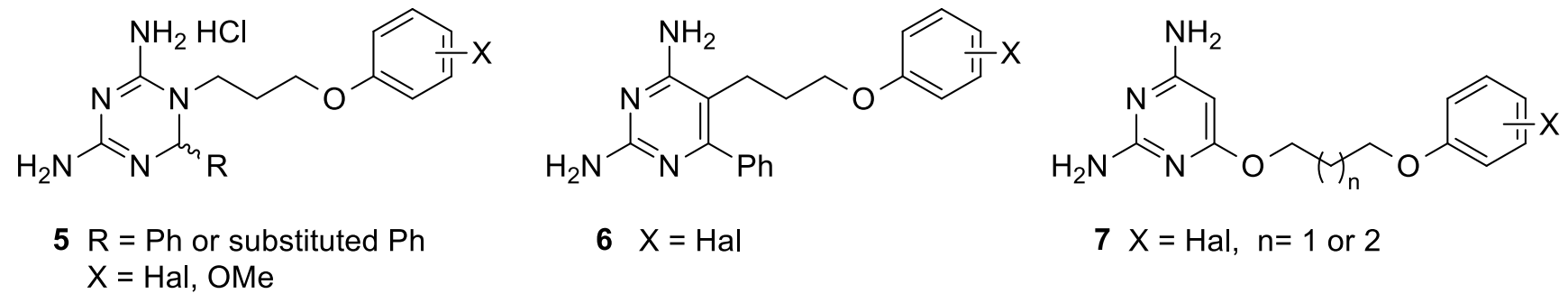

Figure 2. Dihydrotriazines (5) prepared previously, and pyrimidine analogues (6) and (7) prepared in this work.

\section{Results and Discussion}

The dihydrotriazines of general structure (5) that we have prepared previously ${ }^{8}$ contained an atypical phenyl substituent at the 6-position of the dihydrotriazine ring. The majority of known antifolates targeting DHFR (such as those shown in Figure 1) contain a simple alkyl substituent at this position. Owing to the difficulties associated with the synthesis of the dihydrotriazines (5) prepared previously, ${ }^{8-9}$ and the fact that they were isolated as racemic mixtures, we planned to prepare the fully aromatic pyrimidine equivalents which lack the stereogenic centre.

Our approach to the pyrimidine analogues of general structure (6) began with simple alkylation of commercially available phenols (8a-g) with 1,4-dibromobutane to afford the ethers (9a-g) in good yields (Scheme 1 ). Functional-group interconversions by reacting ethers $(\mathbf{9 a - g})$ with potassium cyanide gave pentanenitriles $(10 \mathrm{a}-\mathrm{g})$ in reasonable yields. Reaction of $10 \mathrm{a}-\mathrm{g}$ with ethyl benzoate in the presence of base afforded $\alpha$-cyanoketones (11a-g), once again in good yields.

At this stage, we envisaged utilising methodology reported for the synthesis of 5-ary/pyrimidines ${ }^{10}$ on our substrates (11a-g) to afford the desired 5-alky/pyrimidines. This methodology involved formation of an intermediate enol ether, followed by reaction with guanidine hydrochloride to afford the desired pyrimidine products. Formation of the intermediate enol ethers was achieved by reaction with diazomethane generated in situ from diazald ( $N$-methyl- $N$-nitroso- $p$-toluenesulfonamide) and potassium hydroxide. In general, the enol ethers were used as the crude products in the subsequent reactions with guanidine hydrochloride, after confirmation of the formation of the enol ether by ${ }^{1} \mathrm{H}$ NMR spectroscopy.

Unfortunately, the final reaction with guanidine hydrochloride either afforded the products in low yields or was unsuccessful, possibly due to the lack of an aromatic substituent at the $\alpha$-position of our substrates 11a-g. Of the seven enol ethers prepared, only four were successfully converted into pyrimidine products (6a-d), however, in disappointingly low yields. 


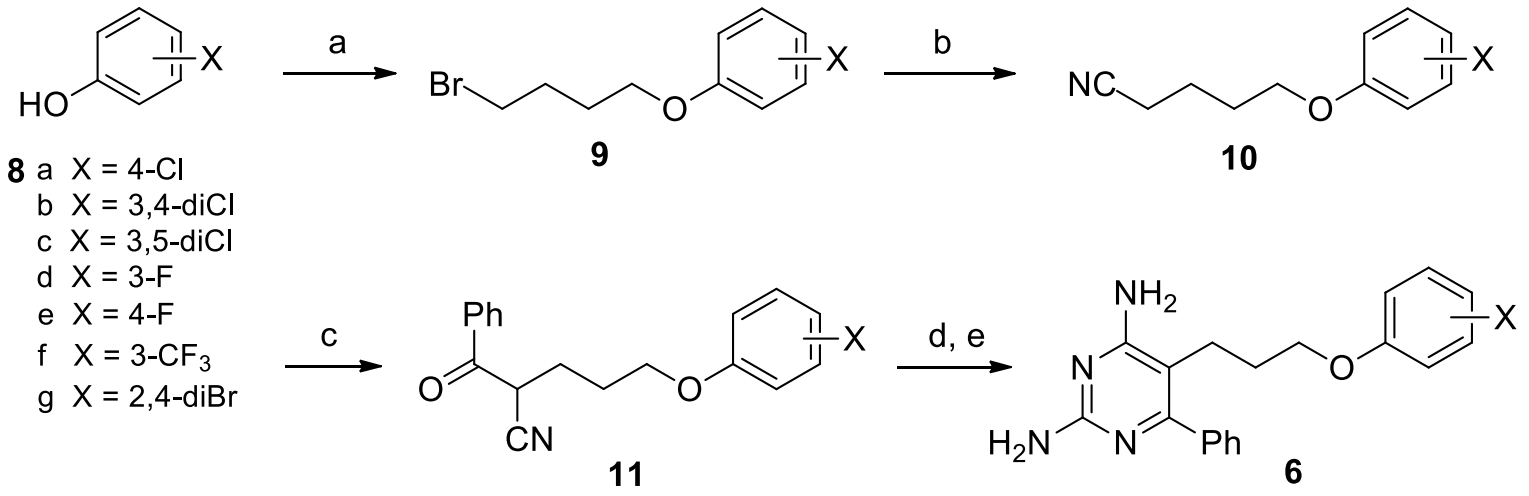

Scheme 1. Reagents, conditions, and yields: (a) 1,4-dibromobutane, $\mathrm{K}_{2} \mathrm{CO}_{3}, \mathrm{CH}_{3} \mathrm{CN}$, reflux, $20 \mathrm{~h}, 63-$ 98\%; (b) KCN, EtOH/ $\mathrm{H}_{2} \mathrm{O}$, reflux, 48 h, 62 - 89\%; (c) ethyl benzoate, $\mathrm{KO}^{t} \mathrm{Bu}, \mathrm{THF}, \mathrm{rt}, 18 \mathrm{~h}, 63$ - 94\%; (d) diazomethane, $\mathrm{CH}_{2} \mathrm{Cl}_{2}, \mathrm{rt}, 18 \mathrm{~h}$; (e) guanidine $\mathrm{HCl}$, DMSO, NaOMe, $90^{\circ} \mathrm{C}, 24 \mathrm{~h}, 9-11 \%$ for $6 a-d$.

Nonetheless, we subjected compounds (6a-d) to an initial in vitro assessment of antiplasmodial activity in a whole cell $P$. falciparum assay, at a single concentration of $20 \mu \mathrm{M}$. The compounds were screened against a cycloguanil-resistant strain (Gambian FCR-3), for direct comparison with our original series of dihydrotriazine compounds (of general structure $(\mathbf{5})^{8}$ ) which had been screened against this strain. At this single concentration, pyrimidines (6a-d) inhibited parasitaemia by more than $45 \%$ in each case (Table 1 ). $I C_{50}$ values were then determined for the compounds from the log sigmoid dose response curves generated by GraphPad Prism ${ }^{\circledR}$ software. Disappointingly, only one of the compounds, 5-(3-(3,5-dichlorophenoxy)propyl)-6-phenylpyrimidine-2,4-diamine (6c) (entry 3, Table $\left.1, I_{50} 0.86 \mu \mathrm{M}\right)$ showed activity in the nanomolar range comparable with the dihydrotriazines ${ }^{8}$ prepared previously. The remainder of the compounds displayed only moderate activity in the low micromolar range. This could be attributed to the inflexibility of the biaryl axis now present between the 6-phenyl substituent and the pyrimidine ring, which was not present in the original series of dihydrotriazines, where the phenyl substituent was bonded to an $\mathrm{sp}^{3}$ hybridised carbon with tetrahedral geometry. Notably, the DHFR inhibitor methotrexate also displayed antiplasmodial activity in the low micromolar range against the cycloguanil-resistant strain (entry 7, Table 1, IC $501.71 \mu \mathrm{M}$ ).

Table 1. Whole cell antiplasmodial activity of analogues $(6 a-d)^{a}$

\begin{tabular}{ccccc}
\hline Entry & Inhibitor & Substituent X & $\begin{array}{c}\text { \% Inhibition of } \\
\text { parasitaemia at } 20 \mu \mathrm{M}\end{array}$ & $\mathrm{IC}_{50}(\mu \mathrm{M})^{\mathrm{b}}$ \\
\hline 1 & $6 \mathrm{a}$ & $4-\mathrm{Cl}$ & $59.84 \pm 12.00$ & $3.69 \pm 0.35$ \\
2 & $6 \mathrm{~b}$ & $3,4-\mathrm{diCl}$ & $48.91 \pm 16.49$ & $14.80 \pm 2.97$ \\
3 & $6 \mathrm{c}$ & $3,5-\mathrm{diCl}$ & $59.94 \pm 24.48$ & $0.86 \pm 0.01$ \\
4 & $6 \mathrm{~d}$ & $3-\mathrm{F}$ & $48.84 \pm 17.33$ & $26.55 \pm 5.84$ \\
6 & Control & $\mathrm{DHA}^{\mathrm{c}}$ & $60.64 \pm 0.17$ & $6.13 \times 10^{-3} \pm 1.11 \times 10^{-3}$ \\
7 & Control & $\mathrm{MTX}^{\mathrm{d}}$ & $59.69 \pm 1.02$ & $1.71 \pm 0.51$ \\
\hline
\end{tabular}

${ }^{a}$ Data are presented as the mean \pm SD of three experiments. ${ }^{b} I_{50}$ values determined by SYBR green assay against the Gambian FCR-3 strain. ${ }^{\mathrm{C}} \mathrm{DHA}=$ Dihydroartemisinin. ${ }^{\mathrm{d}} \mathrm{MTX}=$ Methotrexate 
In another aspect of this work, we wanted to assess the effect of moving the flexible side chain from C-5 to C-6 on the pyrimidine ring. This would eliminate the biaryl axis created by the presence of a phenyl substituent at C-6 as was present in 6a-d, and preliminary modelling studies suggested that the longer flexible chain could place the aromatic substituent at the correct binding position in the DHFR active site. ${ }^{11}$

The preparation of analogues of general structure (7) bearing a modified side chain could be achieved by simple substitution of a 4-hydroxypyrimidine. As shown in Scheme 2, commercially available phenols (8a-d) were alkylated with 1,3-dibromopropane, using the method described previously to afford bromoethers (12ad). 2,4-Diaminopyrimidin-6-ol was then reacted with bromoethers (12a-d) to give pyrimidines (7g-j) bearing a 5-atom linker at the 6-position of the pyrimidine ring in moderate yields. 2,4-Diaminopyrimidin-6-ol was also treated with previously-prepared bromoethers (9a-f) to afford pyrimidines (7a-f) bearing a 6-atom linker at the 6-position of the pyrimidine ring. Pyrimidines $(7 \mathrm{a}-\mathrm{j})$ prepared by this method were then assessed in the whole cell $P$. falciparum screen described previously (Table 2 ).

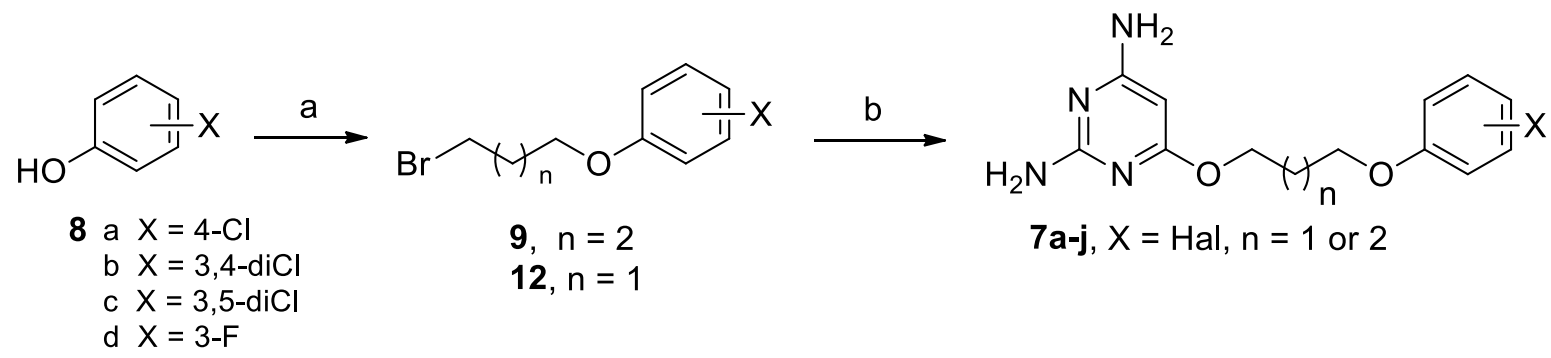

Scheme 2. Reagents, conditions, and yields: (a) For 12 ( $n=1$ ); 1,3-dibromopropane, $\mathrm{K}_{2} \mathrm{CO}_{3}, \mathrm{CH}_{3} \mathrm{CN}$, reflux, $20 \mathrm{~h}$, 87 - 95\%; for 9 ( $n=2$ ); 1,4-dibromobutane, reflux, 20 h, $63-98 \%$; (b) 2,4-diaminopyrimidin-6-ol, $\mathrm{K}_{2} \mathrm{CO}_{3}$, $\mathrm{CH}_{3} \mathrm{CN}$, reflux, $20 \mathrm{~h}, 33-55 \%$.

Table 2. Whole cell antiplasmodial activity of analogues $(\mathbf{7 a - j})^{\mathrm{a}}$

\begin{tabular}{|c|c|c|c|c|c|}
\hline Entry & Inhibitor & $\begin{array}{c}\text { Substituent } \\
\mathrm{X} \\
\end{array}$ & $\mathrm{n}$ & $\begin{array}{c}\% \text { Inhibition of } \\
\text { parasitaemia at } 20 \mu \mathrm{M}\end{array}$ & $I C_{50}(\mu \mathrm{M})^{b}$ \\
\hline 1 & $7 a$ & $4-\mathrm{Cl}$ & 2 & $66.04 \pm 9.4$ & $83.45 \pm 8.36$ \\
\hline 2 & $7 b$ & 3,4-diCl & 2 & $55.15 \pm 5.1$ & $4.46 \pm 0.29$ \\
\hline 3 & 7c & 3,5-diCl & 2 & $40.30 \pm 14.1$ & $22.80 \pm 2.96$ \\
\hline 4 & $7 d$ & $3-F$ & 2 & $53.95 \pm 9.4$ & $11.18 \pm 1.06$ \\
\hline 5 & $7 e$ & $4-\mathrm{F}$ & 2 & $48.18 \pm 5.6$ & $14.96 \pm 1.78$ \\
\hline 6 & $7 f$ & $3-\mathrm{CF}_{3}$ & 2 & $66.90 \pm 3.1$ & $18.02 \pm 2.80$ \\
\hline 7 & $7 g$ & $4-\mathrm{Cl}$ & 1 & $57.36 \pm 4.4$ & $44.88 \pm 7.76$ \\
\hline 8 & 7h & 3,4-diCl & 1 & $52.68 \pm 2.8$ & $11.10 \pm 1.71$ \\
\hline 9 & $7 \mathbf{i}$ & 3,5-diCl & 1 & $33.95 \pm 16.8$ & $7.66 \pm 1.03$ \\
\hline 10 & 7j & $4-\mathrm{F}$ & 1 & $57.50 \pm 8.5$ & $54.74 \pm 10.91$ \\
\hline 11 & Control & $D H A^{c}$ & & $60.64 \pm 0.17$ & $6.13 \times 10^{-3} \pm 1.11 \times 10^{-3}$ \\
\hline 12 & Control & MTX $^{d}$ & & $59.69 \pm 1.02$ & $1.71 \pm 0.51$ \\
\hline
\end{tabular}

${ }^{a}$ Data are presented as the mean \pm SD of three experiments. ${ }^{b} I_{50}$ values determined by SYBR green assay against the Gambian FCR-3 strain. ${ }^{\mathrm{C}} \mathrm{DHA}=$ Dihydroartemisinin. ${ }^{\mathrm{d}} \mathrm{MTX}=$ Methotrexate 
The results presented in Table 2 show that moving the side chain, albeit a modified side chain, to the 6position of the pyrimidine ring, has a detrimental effect on antiplasmodial activity in vitro, with the majority of pyrimidines $(\mathbf{7 a - j})$ being less active than pyrimidines (6a-d) against the drug-resistant strain of the $P$. falciparum parasite. Although from our initial docking studies it appeared that analogues bearing a longer side chain at the 6-position of the pyrimidine ring could adopt a suitable conformation for binding in the DHFR active site, the biological data suggest that this could be energetically unfavourable.

\section{Conclusions}

In summary, we have prepared two series of substituted pyrimidine-2,4-diamines with a flexible side chain at either the 5- or 6-position of the pyrimdine ring as potential inhibitors of $P$. falciparum dihydrofolate reductase (DHFR). The synthesis of the first series of compounds involved construction of the pyrimidine ring by reaction of the enol ether of a suitably substituted $\alpha$-cyanoketone with guanidine hydrochloride while the second series was prepared by substitution of the commercially available 2,4-diaminopyrimidin-6-ol. The compounds prepared were evaluated for antiplasmodial activity in vitro against a cycloguanil-resistant strain of the $P$. falciparum parasite. Compounds bearing a substituent at the 5 -position of the pyrimidine ring showed better activity, in general, than those substituted at the 6-position, with 5-(3-)(3,5dichlorophenoxy)propyl)-6-phenylpyrimidine-2,4-diamine identified as the most active compound in the series $\left(\mathrm{IC}_{50} 0.86 \mu \mathrm{M}\right)$. The remaining pyrimidine-2,4-diamines showed antiplasmodial activity in the micromolar range.

\section{Experimental Section}

\section{Chemistry}

General. Reagents purchased from Sigma-Aldrich (Steinheim, Germany) were of reagent grade and used without any further purification unless specified. Ethyl acetate (EtOAc) and hexane used for chromatography or extractions were distilled prior to use. Dimethyl sulfoxide (DMSO) was distilled and stored over $4 \AA$ molecular sieves. Acetonitrile $\left(\mathrm{CH}_{3} \mathrm{CN}\right)$ was distilled from calcium hydride and tetrahydrofuran (THF) was distilled from sodium prior to use. Reactions were monitored by thin-layer chromatography (TLC) using precoated aluminium-backed plates (Merck silica gel 60 F254) and visualised under UV light ( $\lambda=254 \mathrm{~nm}$ ). Intermediates and final compounds were purified by column chromatography on Fluka silica gel 60 (70-230 mesh). NMR spectra were acquired on a Bruker 300 or $500 \mathrm{MHz}$ spectrometer at room temperature, using the specified deuterated solvent. For those compounds soluble in deuterated chloroform $\left(\mathrm{CDCl}_{3}\right)$, the solvent contained tetramethylsilane (TMS, $0.05 \% \mathrm{v} / \mathrm{v}$ ) as internal standard. For others, the residual solvent signal was used for referencing (MeOD: $3.310 \mathrm{ppm}$; DMSO- $d_{6}$ : $2.500 \mathrm{ppm}$ ). Data processing was done using MestreNova Software under license from Mestrelab Research, CA, USA. Infra-red spectra were recorded on a Bruker Tensor-27 Fourier Transform spectrometer. Mass Spectra (High Resolution) were recorded on a SYNAPT G2 HDMS mass spectrometer (ESI) at Stellenbosch University. Melting points were determined on a Stuart SMP10 melting point apparatus and are uncorrected.

General procedure for the synthesis of (4-bromobutoxy)benzenes (9). To a solution of substituted phenol 8 in dry acetonitrile was added 1,4-dibromobutane ( $3 \mathrm{eq}$ ) and potassium carbonate (1.5 eq). The resultant mixture 
was heated at reflux overnight under a nitrogen atmosphere. After this time, TLC analysis showed consumption of the starting material and the reaction mixture was allowed to cool to room temperature and filtered through celite. The filtrate was concentrated on a rotary evaporator and excess 1,4-dibromobutane was removed by distillation under high vacuum. Compounds were purified by silica gel column chromatography (EtOAc/hexane 20:80).

1-(4-Bromobutoxy)-4-chlorobenzene (9a). ${ }^{9}$ Prepared from 4-chlorophenol (8a) (5.00 g, $\left.38.9 \mathrm{mmol}\right)$, 1,4dibromobutane $(13.9 \mathrm{ml}, 117 \mathrm{mmol})$ and potassium carbonate $(8.06 \mathrm{~g}, 58.3 \mathrm{mmol})$ in dry acetonitrile $(250 \mathrm{ml})$, isolated as a white crystalline solid $(10.0 \mathrm{~g}, 98 \%) . \mathrm{mp} 29-30{ }^{\circ} \mathrm{C} . \mathrm{IR}\left(v_{\max } / \mathrm{cm}^{-1}\right): 2958,1593,1578,1104,823$. ${ }^{1} \mathrm{H}$ NMR $\left(300 \mathrm{MHz}, \mathrm{CDCl}_{3}\right): \delta_{\mathrm{H}} 7.21(2 \mathrm{H}, \mathrm{d}, J 8.9 \mathrm{~Hz}), 6.74(2 \mathrm{H}, \mathrm{d}, J 8.9 \mathrm{~Hz}), 3.93(2 \mathrm{H}, \mathrm{t}, J 6.0 \mathrm{~Hz}), 3.46(2 \mathrm{H}, \mathrm{t}, J 6.5$ $\mathrm{Hz}), 2.14-1.97(2 \mathrm{H}, \mathrm{m}), 1.97-1.84(2 \mathrm{H}, \mathrm{m}) .{ }^{13} \mathrm{C} \mathrm{NMR}\left(75 \mathrm{MHz}, \mathrm{CDCl}_{3}\right): \delta_{\mathrm{C}} 157.5,129.3,125.4,115.7,67.1,33.5$, 29.4, 27.8 .

1-(4-Bromobutoxy)-3,4-dichlorobenzene (9b). ${ }^{9}$ Prepared from 3,4-dichlorophenol (8b) (5.05 g, $\left.31.0 \mathrm{mmol}\right)$, 1,4-dibromobutane $(11.1 \mathrm{ml}, 92.9 \mathrm{mmol})$ and potassium carbonate $(6.42 \mathrm{~g}, 46.5 \mathrm{mmol})$ in dry acetonitrile (250 $\mathrm{ml})$, isolated as a white solid $(8.50 \mathrm{~g}, 92 \%) . \mathrm{mp} 25-27^{\circ} \mathrm{C} . \mathrm{IR}\left(v_{\max } / \mathrm{cm}^{-1}\right): 3041,1578,1145 .{ }^{1} \mathrm{H} \mathrm{NMR}(300 \mathrm{MHz}$, $\left.\mathrm{CDCl}_{3}\right): \delta_{\mathrm{H}} 7.31(1 \mathrm{H}, \mathrm{d}, J 8.9 \mathrm{~Hz}), 6.98(1 \mathrm{H}, \mathrm{d}, J 2.8 \mathrm{~Hz}), 6.74(1 \mathrm{H}, \mathrm{dd}, J$ 8.9, $2.8 \mathrm{~Hz}), 3.96(2 \mathrm{H}, \mathrm{t}, J 5.9 \mathrm{~Hz}), 3.48(2 \mathrm{H}$, $\mathrm{t}, \mathrm{J} 6.4 \mathrm{~Hz}), 2.13-1.86(4 \mathrm{H}, \mathrm{m}) .{ }^{13} \mathrm{C} N M R\left(75 \mathrm{MHz}, \mathrm{CDCl}_{3}\right): \delta_{\mathrm{C}} 157.9,132.9,130.7,124.0,116.3,114.5,67.5,33.2$, 29.3, 27.7.

1-(4-Bromobutoxy)-3,5-dichlorobenzene (9c). ${ }^{9}$ Prepared from 3,5-dichlorophenol (8c) (5.00 g, $\left.30.7 \mathrm{mmol}\right)$, 1,4-dibromobutane $(10.9 \mathrm{ml}, 92.0 \mathrm{mmol})$ and potassium carbonate $(6.36 \mathrm{~g}, 46.0 \mathrm{mmol})$ in dry acetonitrile (250 $\mathrm{ml})$, isolated as a white crystalline solid $(8.02 \mathrm{~g}, 88 \%) . \mathrm{mp} 26-28{ }^{\circ} \mathrm{C} . \mathrm{IR}\left(v_{\max } / \mathrm{cm}^{-1}\right): 2953,1581,1576,1141$. ${ }^{1} \mathrm{H}$ NMR $\left(300 \mathrm{MHz}, \mathrm{CDCl}_{3}\right): \delta_{\mathrm{H}} 6.91(1 \mathrm{H}, \mathrm{t}, J 1.8 \mathrm{~Hz}), 6.75(2 \mathrm{H}, \mathrm{d}, J 1.8 \mathrm{~Hz}), 3.92(2 \mathrm{H}, \mathrm{t}, J 5.9 \mathrm{~Hz}), 3.45(2 \mathrm{H}, \mathrm{t}, J 6.4$ $\mathrm{Hz}), 2.08-1.96(2 \mathrm{H}, \mathrm{m}), 1.96-1.84(2 \mathrm{H}, \mathrm{m}) ;{ }^{13} \mathrm{C} \mathrm{NMR}\left(126 \mathrm{MHz}, \mathrm{CDCl}_{3}\right): \delta_{\mathrm{C}} 160.2,135.6,121.2,113.8,67.8,33.5$, 29.6, 27.9.

1-(4-Bromobutoxy)-3-fluorobenzene (9d). ${ }^{12}$ Prepared from 3-fluorophenol (8d) (5.00 g, $\left.44.6 \mathrm{mmol}\right), 1,4-$ dibromobutane $(15.9 \mathrm{ml}, 134 \mathrm{mmol})$ and potassium carbonate $(9.25 \mathrm{~g}, 66.9 \mathrm{mmol})$ in dry acetonitrile $(250 \mathrm{ml})$, isolated as an oil $(9.51 \mathrm{~g}, 86 \%)$. IR $\left(v_{\max } / \mathrm{cm}^{-1}\right): 2956,1593,1577,1084 .{ }^{1} \mathrm{H} \mathrm{NMR}\left(300 \mathrm{MHz}, \mathrm{CDCl}_{3}\right): \delta_{\mathrm{H}} 7.19(1 \mathrm{H}$, $\mathrm{td}, J$ 8.2, $6.8 \mathrm{~Hz}), 6.71-6.54(3 \mathrm{H}, \mathrm{m}), 3.94(2 \mathrm{H}, \mathrm{t}, J 6.0 \mathrm{~Hz}), 3.46(2 \mathrm{H}, \mathrm{t}, J 6.5 \mathrm{~Hz}), 2.11-1.98(2 \mathrm{H}, \mathrm{m}), 1.98-1.86(2 \mathrm{H}$, m). ${ }^{13} \mathrm{C} \mathrm{NMR}\left(75 \mathrm{MHz}, \mathrm{CDCl}_{3}\right): \delta_{\mathrm{C}} 163.7$ (d, $J_{\mathrm{C}-\mathrm{F}} 245.3 \mathrm{~Hz}$ ), $160.3\left(\mathrm{~d}, J_{\mathrm{C}-\mathrm{F}} 10.8 \mathrm{~Hz}\right.$ ), 130.3 (d, $J_{\mathrm{C}-\mathrm{F}} 10.0 \mathrm{~Hz}$ ), 110.3 $\left(d, J_{C-F} 2.9 \mathrm{~Hz}\right), 107.6\left(\mathrm{~d}, J_{\mathrm{C}-\mathrm{F}} 21.3 \mathrm{~Hz}\right), 102.2\left(\mathrm{~d}, J_{\mathrm{C}-\mathrm{F}} 24.7 \mathrm{~Hz}\right), 67.2,33.4,29.5,27.9$.

1-(4-Bromobutoxy)-4-fluorobenzene (9e). ${ }^{13}$ Prepared from 4-fluorophenol (8e) (5.02 g, $\left.44.8 \mathrm{mmol}\right), 1,4-$ dibromobutane $(16.0 \mathrm{ml}, 134 \mathrm{mmol})$ and potassium carbonate $(9.28 \mathrm{~g}, 67.2 \mathrm{mmol})$ in dry acetonitrile $(250 \mathrm{ml})$, isolated as a white solid $(6.92 \mathrm{~g}, 63 \%) . \mathrm{mp} 32-33^{\circ} \mathrm{C}$. IR $\left(v_{\max } / \mathrm{cm}^{-1}\right): 2930,1599,1578,1133 .{ }^{1} \mathrm{H} \mathrm{NMR}(300 \mathrm{MHz}$, $\left.\mathrm{CDCl}_{3}\right): \delta_{\mathrm{H}} 7.01-6.93(2 \mathrm{H}, \mathrm{m}), 6.86-6.75(2 \mathrm{H}, \mathrm{m}), 3.95(2 \mathrm{H}, \mathrm{t}, J 6.0 \mathrm{~Hz}), 3.48(2 \mathrm{H}, \mathrm{t}, J 6.6 \mathrm{~Hz}), 2.11-2.01(2 \mathrm{H}, \mathrm{m})$, 2.00-1.86 (2H, m). ${ }^{13} \mathrm{C} \mathrm{NMR}\left(75 \mathrm{MHz}, \mathrm{CDCl}_{3}\right): \delta_{\mathrm{C}} 157.3\left(\mathrm{~d}, J_{\mathrm{C}-\mathrm{F}} 238.3 \mathrm{~Hz}\right), 154.9\left(\mathrm{~d}, J_{\mathrm{C}-\mathrm{F}} 2.0 \mathrm{~Hz}\right), 115.8\left(\mathrm{~d}, J_{\mathrm{C}-\mathrm{F}}\right.$ $23.1 \mathrm{~Hz}), 115.4\left(\mathrm{~d}, J_{\mathrm{C}-\mathrm{F}}=8.0 \mathrm{~Hz}\right), 67.4,33.4,29.4,27.9$. HRMS (ESI) found $[\mathrm{M}+\mathrm{Na}]^{+} 268.9953, \mathrm{C}_{10} \mathrm{H}_{12}{ }^{79} \mathrm{BrFONa}$ requires 268.9956.

1-(4-Bromobutoxy)-3-(trifluoromethyl)benzene (9f). ${ }^{14}$ Prepared from 3-(trifluoromethyl)phenol (8f) (7.00 g, $43.2 \mathrm{mmol}), 1$,4-dibromobutane $(15.5 \mathrm{ml}, 126 \mathrm{mmol})$ and potassium carbonate $(8.95 \mathrm{~g}, 64.8 \mathrm{mmol})$ in dry acetonitrile $(250 \mathrm{ml})$, isolated as a pale-yellow oil $(11.5 \mathrm{~g}, 89 \%)$. IR $\left(v_{\mathrm{max}} / \mathrm{cm}^{-1}\right): 2963,1594,1066,1224 .{ }^{1} \mathrm{H}$ NMR $\left(500 \mathrm{MHz}, \mathrm{CDCl}_{3}\right): \delta_{\mathrm{H}}$ 7.39-7.34 $(1 \mathrm{H}, \mathrm{m}), 7.21-7.17(1 \mathrm{H}, \mathrm{m}), 7.13-7.09(1 \mathrm{H}, \mathrm{m}), 7.04(1 \mathrm{H}, \mathrm{dd}, J$ 8.4, $2.7 \mathrm{~Hz}), 4.01$ $(2 \mathrm{H}, \mathrm{t}, J 6.0 \mathrm{~Hz}), 3.48(2 \mathrm{H}, \mathrm{t}, J 6.6 \mathrm{~Hz}), 2.10-2.03(2 \mathrm{H}, \mathrm{m}), 2.00-1.92(2 \mathrm{H}, \mathrm{m}) .{ }^{13} \mathrm{C} \mathrm{NMR}\left(125 \mathrm{MHz}, \mathrm{CDCl}_{3}\right): \delta_{\mathrm{C}}$ 159.1, 131. 9 (q, J J $\left.J_{C-F} 32.2 \mathrm{~Hz}\right), 130.0,124.1$ (q, $\left.J_{C-F} 272.4 \mathrm{~Hz}\right), 118.0,117.4\left(q, J_{C-F} 3.8 \mathrm{~Hz}\right), 111.3\left(q, J_{C-F} 3.7 \mathrm{~Hz}\right)$, $67.2,33.3,29.4,27.8$. 
2,4-Dibromo-1-(4-bromobutoxy)benzene (9g). Prepared from 2,4-dibromophenol (8g) (5.00 g, $19.8 \mathrm{mmol})$, 1,4-dibromobutane $(7.11 \mathrm{ml}, 59.5 \mathrm{mmol})$ and potassium carbonate $(4.12 \mathrm{~g}, 30.0 \mathrm{mmol})$ in dry acetonitrile (260 $\mathrm{ml})$, isolated as a light-brown solid $(6.13 \mathrm{~g}, 80 \%) . \mathrm{mp} \mathrm{30-33}{ }^{\circ} \mathrm{C} . \mathrm{IR}\left(v_{\mathrm{max}} / \mathrm{cm}^{-1}\right): 3042,1583,1095 .{ }^{1} \mathrm{H} \mathrm{NMR}(300$ $\left.\mathrm{MHz}, \mathrm{CDCl}_{3}\right): \delta_{\mathrm{H}} 7.65(1 \mathrm{H}, \mathrm{d}, J 2.4 \mathrm{~Hz}), 7.34(1 \mathrm{H}, \mathrm{dd}, J 8.7,2.4 \mathrm{~Hz}), 6.73(1 \mathrm{H}, \mathrm{d}, J 8.7 \mathrm{~Hz}), 4.01(2 \mathrm{H}, \mathrm{t}, J 5.8 \mathrm{~Hz})$, $3.52(2 \mathrm{H}, \mathrm{t}, J 6.4 \mathrm{~Hz}), 2.16-2.04(2 \mathrm{H}, \mathrm{m}), 2.04-1.93(2 \mathrm{H}, \mathrm{m}) .{ }^{13} \mathrm{C} \mathrm{NMR}\left(75 \mathrm{MHz}, \mathrm{CDCl}_{3}\right): \delta_{\mathrm{C}} 154.6,135.4,131.3$, 114.3, 113.2, 113.1, 68.5, 33.6, 29.4, 27.7. HRMS (ESI): found [M + Na] ${ }^{+} 406.8266, \mathrm{C}_{10} \mathrm{H}_{11}{ }^{79} \mathrm{Br}_{3} \mathrm{ONa}$ requires 406.8258.

General procedure for the synthesis of 5-phenoxypentanenitriles (10). To a solution of the substituted (4bromobutoxy)benzene 9 in ethanol/water (3:1) was added potassium cyanide (1.1 eq). The resulting heterogeneous mixture was stirred and heated at reflux under a nitrogen atmosphere for two days. The reaction progress was monitored by TLC (EtOAc/hexane 40:60). When complete, the reaction mixture was cooled to room temperature, quenched with aq. $\mathrm{NaOH}(0.1 \mathrm{M}, 100 \mathrm{ml})$ and concentrated on a rotary evaporator. The residue was extracted with $\mathrm{CH}_{2} \mathrm{Cl}_{2}(3 \times 100 \mathrm{ml})$, the combined organic layers were dried with $\mathrm{MgSO}_{4}$, filtered through celite and excess solvent was removed on a rotary evaporator. Products were purified by silica gel column chromatography (EtOAc/hexane 10:90 -20:80).

5-(4-Chlorophenoxy)pentanenitrile (10a). Prepared from 1-(4-bromobutoxy)-4-chlorobenzene (9a) (4.00 g, $15.2 \mathrm{mmol})$ and potassium cyanide $(1.10 \mathrm{~g}, 16.7 \mathrm{mmol})$ in ethanol/water $(160 \mathrm{ml})$; isolated as a pale yellow oil $(2.85 \mathrm{~g}, 89 \%)$. IR $\left(v_{\max } / \mathrm{cm}^{-1}\right): 3084,2965,2252,1585,1570 .{ }^{1} \mathrm{H}$ NMR $\left(300 \mathrm{MHz}, \mathrm{CDCl}_{3}\right): \delta_{\mathrm{H}} 7.21(2 \mathrm{H}, \mathrm{d}, J 9.0 \mathrm{~Hz})$, $6.79(2 \mathrm{H}, \mathrm{d}, J 9.0 \mathrm{~Hz}), 3.94(2 \mathrm{H}, \mathrm{t}, J 5.6 \mathrm{~Hz}), 2.41(2 \mathrm{H}, \mathrm{t}, J 6.8 \mathrm{~Hz}), 1.97-1.77(4 \mathrm{H}, \mathrm{m}) .{ }^{13} \mathrm{C} \mathrm{NMR}\left(75 \mathrm{MHz}, \mathrm{CDCl}_{3}\right): \delta_{\mathrm{C}}$ $157.3,129.3,125.6,119.5,115.7,67.0,28.1,22.4,16.9$. HRMS (ESI): found $[\mathrm{M}+\mathrm{Na}]^{+} 232.0500$, $\mathrm{C}_{11} \mathrm{H}_{12}{ }^{35} \mathrm{CINONa}$ requires 232.0507 .

5-(3,4-Dichlorophenoxy)pentanenitrile (10b). Prepared from 1-(4-bromobutoxy)-3,4-dichlorobenzene (9b) $(5.05 \mathrm{~g}, 16.9 \mathrm{mmol})$ and potassium cyanide $(1.21 \mathrm{~g}, 18.6 \mathrm{mmol})$ in ethanol/water $(160 \mathrm{ml})$, isolated as pale yellow oil $(3.55 \mathrm{~g}, 86 \%)$. IR $\left(v_{\max } / \mathrm{cm}^{-1}\right): 3083,2964,2250,1599,1574 .{ }^{1} \mathrm{H} \mathrm{NMR}\left(300 \mathrm{MHz}, \mathrm{CDCl}_{3}\right): \delta_{\mathrm{H}} 7.31(1 \mathrm{H}, \mathrm{d}$, J $8.9 \mathrm{~Hz}), 6.97(1 \mathrm{H}, \mathrm{d}, J 2.8 \mathrm{~Hz}), 6.74(1 \mathrm{H}, \mathrm{dd}, J 8.9,2.8 \mathrm{~Hz}), 3.97(2 \mathrm{H}, \mathrm{t}, J 5.8 \mathrm{~Hz}), 2.44(2 \mathrm{H}, \mathrm{t}, J 7.0 \mathrm{~Hz}), 2.00-1.81$ $(4 \mathrm{H}, \mathrm{m}) .{ }^{13} \mathrm{C}$ NMR $\left(126 \mathrm{MHz}, \mathrm{CDCl}_{3}\right): \delta_{\mathrm{C}} 157.7,132.9,130.7,124.1,119.3,116.3,114.5,67.3,28.0,22.3,17.0$. HRMS (ESI): found [M + Na] ${ }^{+} 266.011, \mathrm{C}_{11} \mathrm{H}_{11}{ }^{35} \mathrm{Cl}_{2} \mathrm{NONa}$ requires 266.0118.

5-(3,5-Dichlorophenoxy)pentanenitrile (10c). Prepared from 1-(4-bromobutoxy)-3,5-dichlorobenzene (9c) $(4.20 \mathrm{~g}, 14.1 \mathrm{mmol})$ and potassium cyanide $(1.01 \mathrm{~g}, 15.5 \mathrm{mmol})$ in ethanol/water $(160 \mathrm{ml})$, isolated as a white solid $(2.45 \mathrm{~g}, 71 \%)$. mp 52-53 ${ }^{\circ} \mathrm{C}$. IR $\left(v_{\max } / \mathrm{cm}^{-1}\right): 3083,2966,2253,1585,1570 .{ }^{1} \mathrm{H} \mathrm{NMR}\left(300 \mathrm{MHz} \mathrm{CDCl}_{3}\right): \delta_{\mathrm{H}}$ $6.96(1 \mathrm{H}, \mathrm{t}, J 1.8 \mathrm{~Hz}), 6.78(2 \mathrm{H}, \mathrm{d}, J 1.8 \mathrm{~Hz}), 3.98(2 \mathrm{H}, \mathrm{t}, J 5.6 \mathrm{~Hz}), 2.45(2 \mathrm{H}, \mathrm{t}, J 6.8 \mathrm{~Hz}), 2.0-1.80(4 \mathrm{H}, \mathrm{m}) .{ }^{13} \mathrm{C} \mathrm{NMR}$ $\left(75 \mathrm{MHz}, \mathrm{CDCl}_{3}\right): \delta_{\mathrm{C}} 159.7,135.5,121.3,119.3,113.6,67.3,28.0,22.3,17.0$. HRMS (ESI): found [M + Na] $]^{+}$ 266.0115, $\mathrm{C}_{11} \mathrm{H}_{11}{ }^{35} \mathrm{Cl}_{2} \mathrm{NONa}$ requires 266.0118 .

5-(3-Fluorophenoxy)pentanenitrile (10d). Prepared from 1-(4-bromobutoxy)-3-fluorobenzene (9d) (5.00 g, $20.2 \mathrm{mmol}$ ) and potassium cyanide $(1.58 \mathrm{~g}, 24.3 \mathrm{mmol})$ in ethanol/water $(160 \mathrm{ml})$, isolated as a brown oil (3.22 g, 72\%). IR $\left(v_{\max } / \mathrm{cm}^{-1}\right): 2961,2932,2239,1596,1503 .{ }^{1} \mathrm{H} N M R\left(300 \mathrm{MHz}, \mathrm{CDCl}_{3}\right): \delta_{\mathrm{H}} 7.26-7.14(1 \mathrm{H}, \mathrm{m}), 6.70-$ $6.55(3 \mathrm{H}, \mathrm{m}), 3.95(2 \mathrm{H}, \mathrm{t}, J 5.6 \mathrm{~Hz}), 2.41(2 \mathrm{H}, \mathrm{t}, J 6.8 \mathrm{~Hz}), 1.99-1.75(4 \mathrm{H}, \mathrm{m}) .{ }^{13} \mathrm{C} \mathrm{NMR}\left(75 \mathrm{MHz}, \mathrm{CDCl}_{3}\right): \delta_{\mathrm{C}} 163.7$ $\left(\mathrm{d}, J_{\mathrm{C}-\mathrm{F}}=245.7 \mathrm{~Hz}\right), 160.1\left(\mathrm{~d}, J_{\mathrm{C}-\mathrm{F}}=10.8 \mathrm{~Hz}\right), 130.4\left(\mathrm{~d}, J_{\mathrm{C}-\mathrm{F}}=10.1 \mathrm{~Hz}\right), 119.5,110.3\left(\mathrm{~d}, J_{\mathrm{C}-\mathrm{F}}=3.0 \mathrm{~Hz}\right), 107.8\left(\mathrm{~d}, J_{\mathrm{C}-\mathrm{F}}=\right.$ $21.4 \mathrm{~Hz}$ ), $102.2\left(\mathrm{~d}, J_{\mathrm{C}-\mathrm{F}}=24.8 \mathrm{~Hz}\right), 67.0,28.2,22.5,17.1$. HRMS (ESI): found $[\mathrm{M}+\mathrm{Na}]^{+} 216.0807, \mathrm{C}_{11} \mathrm{H}_{12} \mathrm{FNONa}$ requires 216.0803 .

5-(4-Fluorophenoxy)pentanenitrile (10e). Prepared from 1-(4-bromobutoxy)-4-fluorobenzene (9e) (4.00 g, $16.2 \mathrm{mmol})$ and potassium cyanide $(1.20 \mathrm{~g}, 17.8 \mathrm{mmol})$ in ethanol/water $(160 \mathrm{ml})$, isolated as a white solid $(1.93 \mathrm{~g}, 62 \%) \cdot \mathrm{mp} 26-27{ }^{\circ} \mathrm{C} . \mathrm{IR}\left(v_{\max } / \mathrm{cm}^{-1}\right): 2960,2933,2240,1596,1503 .{ }^{1} \mathrm{H} \mathrm{NMR}\left(300 \mathrm{MHz}, \mathrm{CDCl}_{3}\right): \delta_{\mathrm{H}} 7.09-$ $6.88(2 \mathrm{H}, \mathrm{m}), 6.88-6.71(2 \mathrm{H}, \mathrm{m}), 3.96(2 \mathrm{H}, \mathrm{t}, J 5.5 \mathrm{~Hz}), 2.44(2 \mathrm{H}, \mathrm{t}, J 6.6 \mathrm{~Hz}), 2.04-1.76(4 \mathrm{H}, \mathrm{m}) .{ }^{13} \mathrm{C} \mathrm{NMR}(75$ 


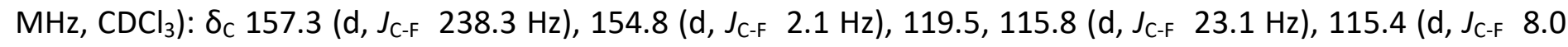
$\mathrm{Hz}), 67.3,28.2,22.5,17.0$. HRMS (ESI): found [M + Na] ${ }^{+} 216.0809, \mathrm{C}_{11} \mathrm{H}_{12} \mathrm{FNONa}$ requires 216.0803 .

5-(3-(Trifluoromethyl)phenoxy)pentanenitrile (10f). Prepared from 1-(4-bromobutoxy)-3(trifluoromethyl)benzene (9f) $(6.00 \mathrm{~g}, 20.2 \mathrm{mmol})$ and potassium cyanide $(1.45 \mathrm{~g}, 22.2 \mathrm{mmol})$ in ethanol/water $(160 \mathrm{ml})$, isolated as a yellow oil $(3.65 \mathrm{~g}, 74 \%)$. IR $\left(v_{\max } / \mathrm{cm}^{-1}\right): 3039,2930,2239,1599 .{ }^{1} \mathrm{H} \mathrm{NMR}(300 \mathrm{MHz}$, $\left.\mathrm{CDCl}_{3}\right): \delta_{\mathrm{H}} 7.37(1 \mathrm{H}, \mathrm{t}, J 8.1 \mathrm{~Hz}), 7.23-7.16(1 \mathrm{H}, \mathrm{m}), 7.12(1 \mathrm{H}, \mathrm{br} \mathrm{s}), 7.05(1 \mathrm{H}, \mathrm{dd}, J$ 8.3, $2.6 \mathrm{~Hz}), 4.01(2 \mathrm{H}, \mathrm{t}, J 5.7$ $\mathrm{Hz}), 2.42(2 \mathrm{H}, \mathrm{t}, J 6.8 \mathrm{~Hz}), 2.04-1.73(4 \mathrm{H}, \mathrm{m}) .{ }^{13} \mathrm{C} \mathrm{NMR}\left(75 \mathrm{MHz}, \mathrm{CDCl}_{3}\right): \delta_{\mathrm{C}} 158.9,132.0\left(\mathrm{q}, J_{\mathrm{C}-\mathrm{F}} 32.3 \mathrm{~Hz}\right), 130.1$, $124.0\left(q, J_{C-F} 272.3 \mathrm{~Hz}\right), 119.5,118.0,117.7\left(q, J_{C-F} 3.9 \mathrm{~Hz}\right), 111.3\left(q, J_{C-F} 3.9 \mathrm{~Hz}\right), 67.0,28.2,22.5,17.1$. HRMS (ESI): found $[\mathrm{M}+\mathrm{Na}]^{+} 266.0773, \mathrm{C}_{12} \mathrm{H}_{12} \mathrm{~F}_{3} \mathrm{NONa}$ requires 266.0771 .

5-(2,4-Dibromophenoxy)pentanenitrile (10g). Prepared from 2,4-dibromo-1-(4-bromobutoxy)benzene (9g) $(5.00 \mathrm{~g}, 12.9 \mathrm{mmol})$ and potassium cyanide $(1.01 \mathrm{~g}, 15.5 \mathrm{mmol}, 1.2 \mathrm{eq})$ in ethanol/water $(160 \mathrm{ml})$, isolated as white solid (3.12 g, 73\%). mp 49-50 ${ }^{\circ} \mathrm{C}$. IR $\left(v_{\max } / \mathrm{cm}^{-1}\right)$ : 3091, 2948, 2253, 1580, 1480. ${ }^{1} \mathrm{H} \mathrm{NMR}\left(300 \mathrm{MHz} \mathrm{CDCl}_{3}\right)$ : $\delta_{\mathrm{H}} 7.66(1 \mathrm{H}, \mathrm{d}, J 2.4 \mathrm{~Hz}), 7.36(1 \mathrm{H}, \mathrm{dd}, J 8.8,2.4 \mathrm{~Hz}), 6.74(1 \mathrm{H}, \mathrm{d}, J 8.8 \mathrm{~Hz}), 4.04(2 \mathrm{H}, \mathrm{t}, J 5.4 \mathrm{~Hz}), 2.50(2 \mathrm{H}, \mathrm{t}, J 6.7$ $\mathrm{Hz}), 2.03-1.89(4 \mathrm{H}, \mathrm{m}) .{ }^{13} \mathrm{C} \mathrm{NMR}\left(75 \mathrm{MHz}, \mathrm{CDCl}_{3}\right): \delta_{\mathrm{C}} 154.4,135.5,131.2,119.5,114.2,113.2,113.1,68.3,27.9$, 22.5, 17.1. HRMS (ESI): found [M + Na] ${ }^{+} 353.9108, \mathrm{C}_{11} \mathrm{H}_{11}{ }^{79} \mathrm{Br}_{2} \mathrm{NONa}$ requires 353.9107.

General procedure for the synthesis of 2-benzoyl-5-phenoxypentanenitriles (11). To a solution of the substituted 5-phenoxypentanenitrile $\mathbf{1 0}$ (1 eq) in dry THF was added potassium tert-butoxide ( 3 eq) and ethyl benzoate $(4 \mathrm{eq})$. The reaction mixture was stirred at room temperature under a nitrogen atmosphere overnight. After consumption of the starting material, the reaction was quenched with sat. aq. $\mathrm{NH}_{4} \mathrm{Cl}$ and $\mathrm{THF}$ removed under reduced pressure. The remaining aqueous residue was washed with EtOAc $(3 \times 100 \mathrm{ml})$ and the organic layers were combined, dried over $\mathrm{MgSO}_{4}$ and filtered through celite. Crude products were purified by column chromatography (EtOAc/hexane 20:80).

2-Benzoyl-5-(4-chlorophenoxy)pentanenitrile (11a). Prepared from 5-(4-chlorophenoxy)pentanenitrile (10a) $(2.32 \mathrm{~g}, 11.1 \mathrm{mmol})$, potassium tert-butoxide $(3.72 \mathrm{~g}, 33.2 \mathrm{mmol})$ and ethyl benzoate $(6.33 \mathrm{ml}, 44.3 \mathrm{mmol}) \mathrm{in}$ dry THF $(50 \mathrm{ml})$, isolated as yellow crystals $(2.82 \mathrm{~g}, 81 \%) . \mathrm{mp} 124-126^{\circ} \mathrm{C}$. IR $\left(v_{\max } / \mathrm{cm}^{-1}\right): 2878,2253,1694$, 1596, 1580. ${ }^{1} \mathrm{H}$ NMR $\left(300 \mathrm{MHz}, \mathrm{CDCl}_{3}\right): \delta_{\mathrm{H}} 7.97(2 \mathrm{H}, \mathrm{d}, J 7.2 \mathrm{~Hz}), 7.65(1 \mathrm{H}, \mathrm{t}, J 7.4 \mathrm{~Hz}), 7.52(2 \mathrm{H}, \mathrm{dd}, J 8.3,6.9$ $\mathrm{Hz}), 7.21(2 \mathrm{H}, \mathrm{d}, J 9.0 \mathrm{~Hz}), 6.77(2 \mathrm{H}, \mathrm{d}, J 9.0 \mathrm{~Hz}), 4.48(1 \mathrm{H}, \mathrm{dd}, J$ 8.4, 5.7 Hz), 4.04-3.99 $(2 \mathrm{H}, \mathrm{m}), 2.37-1.99(4 \mathrm{H}$, m). ${ }^{13} \mathrm{C}$ NMR $\left(75 \mathrm{MHz} \mathrm{CDCl}_{3}\right): \delta_{\mathrm{C}} 190.4,157.1,134.6,133.9,129.4,129.2,128.8,125.9,117.1,115.7,67.0$, 39.4, 26.7, 26.5. HRMS (ESI): found [M + Na] $336.0757, \mathrm{C}_{18} \mathrm{H}_{16}{ }^{35} \mathrm{CINO}_{2} \mathrm{Na}$ requires 336.0770.

2-Benzoyl-5-(3,4-dichlorophenoxy)pentanenitrile (11b). Prepared from 5-(3,4-dichlorophenoxy)pentanenitrile (10b) (2.50 g, $10.2 \mathrm{mmol})$, potassium tert-butoxide $(3.45 \mathrm{~g}, 30.7 \mathrm{mmol})$ and ethyl benzoate $(5.89 \mathrm{ml}, 40.9$ $\mathrm{mmol}$ ) in dry THF $(60 \mathrm{ml})$, isolated as a white solid $(3.34 \mathrm{~g}, 94 \%) . \mathrm{mp} 43-44^{\circ} \mathrm{C} . \mathrm{IR}\left(v_{\mathrm{max}} / \mathrm{cm}^{-1}\right): 3041,2954,2252$, 1695, 1586, 1574. ${ }^{1} \mathrm{H}$ NMR $\left(500 \mathrm{MHz}, \mathrm{CDCl}_{3}\right): \delta_{\mathrm{H}} 7.96(2 \mathrm{H}, \mathrm{d}, J 6.9 \mathrm{~Hz}), 7.69-7.61(1 \mathrm{H}, \mathrm{m}), 7.51(2 \mathrm{H}, \mathrm{t}, J 8.0 \mathrm{~Hz})$, $7.28(1 \mathrm{H}, \mathrm{dd}, J$ 8.7, $2.9 \mathrm{~Hz}), 6.91(1 \mathrm{H}, \mathrm{s}), 6.73-6.67(1 \mathrm{H}, \mathrm{m}), 4.64-4.40(1 \mathrm{H}, \mathrm{m}), 4.07-3.92(2 \mathrm{H}, \mathrm{m}), 2.34-2.12(2 \mathrm{H}$, m), 2.12-1.95 (2H, m). ${ }^{13} \mathrm{C}$ NMR $\left(126 \mathrm{MHz}_{1} \mathrm{CDCl}_{3}\right): \delta_{\mathrm{C}} 190.6,157.6,134.6,133.9,132.8,130.7,129.2,128.8$, 124.1, 117.3, 116.4, 114.4, 67.3, 39.5, 26.6, 26.4. HRMS (ESI): found [M + Na] ${ }^{+} 370.0377, \mathrm{C}_{18} \mathrm{H}_{15}{ }^{35} \mathrm{Cl}_{2} \mathrm{NO}_{2} \mathrm{Na}$ requires 370.0380 .

2-Benzoyl-5-(3,5-dichlorophenoxy)pentanenitrile (11c). Prepared from 5-(3,5-dichlorophenoxy)pentanenitrile (10c) $(1.98 \mathrm{~g}, 8.11 \mathrm{mmol})$, potassium tert-butoxide $(2.73 \mathrm{~g}, 24.3 \mathrm{mmol})$ and ethyl benzoate $(4.64 \mathrm{ml}, 32.4$ $\mathrm{mmol})$ in dry THF $(40 \mathrm{ml})$, isolated as a light yellow solid $(2.80 \mathrm{~g}, 91 \%) . \mathrm{mp} 45-46{ }^{\circ} \mathrm{C} . \mathrm{IR}\left(v_{\max } / \mathrm{cm}^{-1}\right): 2889,2255$, 1697, 1582, 1570. ${ }^{1} \mathrm{H}$ NMR $\left(300 \mathrm{MHz}, \mathrm{CDCl}_{3}\right): \delta_{\mathrm{H}} 7.97(2 \mathrm{H}, \mathrm{d}, J 7.1 \mathrm{~Hz}), 7.74-7.61(1 \mathrm{H}, \mathrm{m}), 7.53(2 \mathrm{H}, \mathrm{dd}, J 8.3,7.0$ $\mathrm{Hz}), 6.95(1 \mathrm{H}, \mathrm{t}, J 1.8 \mathrm{~Hz}), 6.72(2 \mathrm{H}, \mathrm{d}, J 1.8 \mathrm{~Hz}), 4.46(1 \mathrm{H}, \mathrm{dd}, J$ 8.1, 5.9 Hz), 4.06-3.88 (2H, m), 2.36-1.82 (4H, m). 
${ }^{13} \mathrm{C} \mathrm{NMR}\left(75 \mathrm{MHz}, \mathrm{CDCl}_{3}\right): \delta_{\mathrm{C}} 190.2,159.5,135.5(2 \mathrm{C}), 134.7,133.9,129.2,128.8,121.3,117.0,113.6,113.5$, 67.3, 39.3, 26.5, 26.4. HRMS (ESI): found [M + Na] ${ }^{+} 370.0381, \mathrm{C}_{18} \mathrm{H}_{15}{ }^{35} \mathrm{Cl}_{2} \mathrm{NO}_{2} \mathrm{Na}$ requires 370.0380 .

2-Benzoyl-5-(3-fluorophenoxy)pentanenitrile (11d). Prepared from 5-(3-fluorophenoxy)pentanenitrile (10d) $(4.88 \mathrm{~g}, 25.3 \mathrm{mmol})$, potassium tert-butoxide $(8.50 \mathrm{~g}, 75.8 \mathrm{mmol})$ and ethyl benzoate $(14.4 \mathrm{ml}, 101 \mathrm{mmol})$ in dry THF $(70 \mathrm{ml})$, isolated as a yellow solid $(6.53 \mathrm{~g}, 87 \%) . \mathrm{mp} 32{ }^{\circ} \mathrm{C} . \mathrm{IR}\left(v_{\max } / \mathrm{cm}^{-1}\right) 2876,2254,1689,1596,1576$. ${ }^{1} \mathrm{H}$ NMR $\left(300 \mathrm{MHz}, \mathrm{CDCl}_{3}\right): \delta_{\mathrm{H}} 7.96(2 \mathrm{H}, \mathrm{d}, J 7.1 \mathrm{~Hz}), 7.70-7.59(1 \mathrm{H}, \mathrm{m}), 7.51(2 \mathrm{H}, \mathrm{dd}, J 8.4,7.1 \mathrm{~Hz}), 7.28-7.12$ $(1 \mathrm{H}, \mathrm{m}), 6.73-6.46(3 \mathrm{H}, \mathrm{m}), 4.50(1 \mathrm{H}, \mathrm{dd}, J$ 8.4, $5.7 \mathrm{~Hz}), 4.04-3.92(2 \mathrm{H}, \mathrm{m}), 2.36-1.99(4 \mathrm{H}, \mathrm{m}) .{ }^{13} \mathrm{C} \mathrm{NMR}(75 \mathrm{MHz}$, $\mathrm{CDCl}_{3}$ ): $\delta_{\mathrm{C}} 190.5,163.6\left(\mathrm{~d}, J_{\mathrm{C}-\mathrm{F}} 245.3 \mathrm{~Hz}\right), 159.9\left(\mathrm{~d}, J_{\mathrm{C}-\mathrm{F}} 10.8 \mathrm{~Hz}\right), 134.6,133.9,130.3\left(\mathrm{~d}, J_{\mathrm{C}-\mathrm{F}} 10.0 \mathrm{~Hz}\right), 129.1$, 128.8, 117.2, 110.2 (d, $J_{C-F} 2.9 \mathrm{~Hz}$ ), 107.8 (d, $J_{\mathrm{C}-\mathrm{F}} 21.3 \mathrm{~Hz}$ ), 102.2 (d, $J_{\mathrm{C}-\mathrm{F}} 24.8 \mathrm{~Hz}$ ), 66.9, 39.4, 26.7, 26.4. HRMS (ESI): found $[\mathrm{M}+\mathrm{Na}]^{+} 320.1063, \mathrm{C}_{18} \mathrm{H}_{16} \mathrm{FNO}_{2} \mathrm{Na}$ requires 320.1065 .

2-Benzoyl-5-(4-fluorophenoxy)pentanenitrile (11e). Prepared from 5-(4-fluorophenoxy)pentanenitrile (10e) $(1.55 \mathrm{~g}, 8.02 \mathrm{mmol})$, potassium tert-butoxide $(2.70 \mathrm{~g}, 24.1 \mathrm{mmol})$ and ethyl benzoate $(4.60 \mathrm{ml}, 32.1 \mathrm{mmol})$ in dry THF (45 ml), isolated as a yellow solid (1.99 g, 83\%). $\mathrm{mp} 86-87^{\circ} \mathrm{C} . \mathrm{IR}\left(v_{\max } / \mathrm{cm}^{-1}\right): 2956,2930,2252,1703$, 1586, 1577. ${ }^{1} \mathrm{H}$ NMR $\left(300 \mathrm{MHz}, \mathrm{CDCl}_{3}\right): \delta_{\mathrm{H}} 8.04-7.90(2 \mathrm{H}, \mathrm{m}), 7.72-7.57(1 \mathrm{H}, \mathrm{m}), 7.51(2 \mathrm{H}, \mathrm{dd}, J 8.4,7.1 \mathrm{~Hz})$, 7.03-6.90 $(2 \mathrm{H}, \mathrm{m}), 6.87-6.70(2 \mathrm{H}, \mathrm{m}), 4.50(1 \mathrm{H}, \mathrm{dd}, J 8.5,5.7 \mathrm{~Hz}), 4.08-3.93(2 \mathrm{H}, \mathrm{m}), 2.34-1.78(4 \mathrm{H}, \mathrm{m}) .{ }^{13} \mathrm{C} \mathrm{NMR}$ $\left(75 \mathrm{MHz}, \mathrm{CDCl}_{3}\right): \delta_{\mathrm{C}} 190.4,157.4\left(\mathrm{~d}, J_{\mathrm{C}-\mathrm{F}} 238.7 \mathrm{~Hz}\right), 154.6\left(\mathrm{~d}, J_{\mathrm{C}-\mathrm{F}} 2.1 \mathrm{~Hz}\right), 134.6,133.9,129.1,128.8,117.2$, $115.8\left(d, J_{C-F} 23.1 \mathrm{~Hz}\right), 115.4\left(\mathrm{~d}, J_{\mathrm{C}-\mathrm{F}} 8.0 \mathrm{~Hz}\right.$ ), 67.3, 39.4, 26.8, 26.6. HRMS (ESI): found [M + Na] ${ }^{+}$320.1100, $\mathrm{C}_{18} \mathrm{H}_{16} \mathrm{FNO}_{2} \mathrm{Na}$ requires 320.1065 .

\section{2-Benzoyl-5-(3-(trifluoromethyl)phenoxy)pentanenitrile (11f). Prepared from 5-(3-} (trifluoromethyl)phenoxy)pentanenitrile (10f) $(2.50 \mathrm{~g}, 10.3 \mathrm{mmol})$, potassium tert-butoxide $(3.46 \mathrm{~g}, 30.8$ $\mathrm{mmol})$ and ethyl benzoate $(5.88 \mathrm{ml}, 41.1 \mathrm{mmol})$ in dry THF $(60 \mathrm{ml})$, isolated as a yellow viscous oil $(2.24 \mathrm{~g}$, 63\%). IR $\left(v_{\max } / \mathrm{cm}^{-1}\right): 2941,2249,1696,1592,1571 .{ }^{1} \mathrm{H} \mathrm{NMR}\left(300 \mathrm{MHz}, \mathrm{CDCl}_{3}\right): \delta_{\mathrm{H}} 7.97(2 \mathrm{H}, \mathrm{d}, J 7.3 \mathrm{~Hz}), 7.66$ $(1 \mathrm{H}, \mathrm{t}, J 7.4 \mathrm{~Hz}), 7.52(2 \mathrm{H}, \mathrm{t}, J 7.7 \mathrm{~Hz}), 7.38(1 \mathrm{H}, \mathrm{t}, J 7.9 \mathrm{~Hz}), 7.21(1 \mathrm{H}, \mathrm{d}, J 7.7 \mathrm{~Hz}), 7.08-6.96(2 \mathrm{H}, \mathrm{m}), 4.49(1 \mathrm{H}$, $\mathrm{dd}, J$ 8.2, $5.8 \mathrm{~Hz}), 4.16-4.00(2 \mathrm{H}, \mathrm{m}), 2.40-2.00(4 \mathrm{H}, \mathrm{m}) .{ }^{13} \mathrm{C} \mathrm{NMR}\left(75 \mathrm{MHz}, \mathrm{CDCl}_{3}\right): \delta_{\mathrm{C}} 190.3,158.6,134.6,134.0$, 131.9 (q, $J_{C-F} 32.3 \mathrm{~Hz}$ ), 130.1, 129.2, 128.8, 123.9 (q, $J_{\mathrm{C}-\mathrm{F}} 272.4 \mathrm{~Hz}$ ), 117.8, 117.7 (q, $J_{\mathrm{C}-\mathrm{F}} 3.9 \mathrm{~Hz}$ ), 117.1, 111.3 (q, $\left.J_{C-F} 3.8 \mathrm{~Hz}\right), 67.0,39.3,26.7,26.5$. HRMS (ESI): found $[\mathrm{M}+\mathrm{H}]^{+} 348.1227, \mathrm{C}_{19} \mathrm{H}_{17} \mathrm{~F}_{3} \mathrm{NO}_{2}$ requires 348.1213 .

2-Benzoyl-5-(2,4-dibromophenoxy)pentanenitrile $\quad \mathbf{( 1 1 g )}$ Prepared from 5-(2,4dibromophenoxy)pentanenitrile $(\mathbf{1 0 g})(2.94 \mathrm{~g}, 8.83 \mathrm{mmol})$, potassium tert-butoxide $(2.97 \mathrm{~g}, 26.5 \mathrm{mmol})$ and ethyl benzoate $(5.05 \mathrm{ml}, 35.3 \mathrm{mmol})$ in dry THF $(50 \mathrm{ml})$, isolated as a yellow solid $(3.03 \mathrm{~g}, 79 \%) . \mathrm{mp} 35-36{ }^{\circ} \mathrm{C}$. IR $\left(v_{\text {max }} / \mathrm{cm}^{-1}\right): 3010,2255,1699,1578,1569 .{ }^{1} \mathrm{H}$ NMR $\left(500 \mathrm{MHz}, \mathrm{CDCl}_{3}\right): \delta_{\mathrm{H}} 8.00(2 \mathrm{H}, \mathrm{d}, J 7.0 \mathrm{~Hz}), 7.70-7.61(2 \mathrm{H}$, m), 7.56-7.47 (2H, m), $7.37(1 \mathrm{H}, \mathrm{d}, J 7.9 \mathrm{~Hz}), 6.76(1 \mathrm{H}, \mathrm{dd}, J 8.9,2.9 \mathrm{~Hz}), 4.66(1 \mathrm{H}, \mathrm{p}, J 3.8 \mathrm{~Hz}), 4.19-4.00(2 \mathrm{H}, \mathrm{m})$, 2.43-2.18 (2H, m), 2.19-2.06 (2H, m). ${ }^{13} \mathrm{C} N M R\left(126 \mathrm{MHz}_{\mathrm{CDCl}}\right): \delta_{\mathrm{C}} 190.7,154.2,135.5,134.6,133.9,131.3$, 129.1, 128.9, 117.3, 114.2, 113.3, 113.0, 68.4, 39.8, 26.9, 26.3. HRMS (ESI): found [M + Na] ${ }^{+} 457.9370$, $\mathrm{C}_{18} \mathrm{H}_{15}{ }^{79} \mathrm{Br}_{2} \mathrm{NO}_{2} \mathrm{Na}$ requires 457.9270 .

General procedure for the synthesis of 6-phenylpyrimidine-2,4-diamines (6). Carbitol, diethyl ether and aqueous potassium hydroxide $(10.7 \mathrm{M}, 20.0 \mathrm{eq})$ were placed in a diazomethane apparatus fitted with a condenser and a dropping funnel containing diazald (3.0 eq) dissolved in diethyl ether. The diazomethane apparatus was lowered into a water bath at 70-80 ${ }^{\circ} \mathrm{C}$. Diazomethane gas, generated from the reaction of diazald and the above reaction mixture was passed into a flask containing the starting material $11 \mathrm{a}-\mathrm{g}$ (1.0 eq), in dry dichloromethane $(50 \mathrm{ml})$. Diethyl ether $(10 \mathrm{ml})$ was used to rinse the dropping funnel. After distillation was complete, the reaction mixture was left to stir at room temperature overnight. Any excess diazomethane was quenched with glacial acetic acid. The reaction was evaporated to dryness in vacuo to give the crude product, which was taken to the next step without further purification. Partial characterisation of the 
intermediate enol ethers was done by ${ }^{1} \mathrm{H}$ and ${ }^{13} \mathrm{C}$ NMR spectroscopy (exemplified in the synthesis of $6 a$ below). In the subsequent step, guanidine hydrochloride was treated with sodium methoxide (2.0 eq) in methanol $(20 \mathrm{ml})$ to furnish free guanidine after filtration and removal of methanol in vacuo. The enol ether prepared in the first step $(1.0 \mathrm{eq})$ was dissolved in dry DMSO and then added to the flask containing free guanidine. The reaction mixture was then heated at $80-100{ }^{\circ} \mathrm{C}$ overnight. After formation of a new product spot visible by TLC, the reaction mixture was heated to $120^{\circ} \mathrm{C}$ to remove DMSO under vacuum. The resulting solid residue was dissolved in a methanol-ethyl acetate mixture and purified by column chromatography (EtOAc/hexane 20:80) to give the desired pyrimidine product 6.

5-(3-(4-Chlorophenoxy)propyl)-6-phenylpyrimidine-2,4-diamine (6a). Diazomethane gas, produced from the reaction of diazald $(2.05 \mathrm{~g}, 9.56 \mathrm{mmol})$ with potassium hydroxide solution $(10.7 \mathrm{M}, 6 \mathrm{ml})$, in a mixture of carbitol $(4 \mathrm{ml})$ and diethyl ether $(20 \mathrm{ml})$ was passed through a solution of 2-benzoyl-5-(4-chlorophenoxy)pentanenitrile (11a) (2.10 g, $3.19 \mathrm{mmol})$, in dry DCM. The resulting enol ether was isolated as a mixture of $E$ and $Z$ isomers in a ratio of 1.4:1. Major isomer: ${ }^{1} \mathrm{H} N M R\left(300 \mathrm{MHz}, \mathrm{CDCl}_{3}\right): \delta_{\mathrm{H}} 7.56-7.33(4 \mathrm{H}, \mathrm{m}), 7.23-7.18(1 \mathrm{H}$, m), $7.23(2 \mathrm{H}, \mathrm{d}, J 9.1 \mathrm{~Hz}), 6.84(2 \mathrm{H}, \mathrm{d}, J 9.0 \mathrm{~Hz}), 4.00(2 \mathrm{H}, \mathrm{t}, J 6.1 \mathrm{~Hz}), 3.43(3 \mathrm{H}, \mathrm{s}), 2.57(2 \mathrm{H}, \mathrm{dd}, J 8.2,6.7 \mathrm{~Hz})$, 2.11-2.01 (2H, m). ${ }^{13} \mathrm{C} \mathrm{NMR}\left(75 \mathrm{MHz}, \mathrm{CDCl}_{3}\right): \delta_{\mathrm{C}} 168.9,157.6,131.5,130.5,129.3,128.9,128.8,125.5,120.1$, 115.8, 94.2, 67.1, 58.3, 28.1, 25.0. Minor isomer: ${ }^{1} \mathrm{H}$ NMR $\left(300 \mathrm{MHz}, \mathrm{CDCl}_{3}\right): \delta_{\mathrm{H}} 7.56-7.33(4 \mathrm{H}, \mathrm{m}), 7.23-7.18$ $(1 \mathrm{H}, \mathrm{m}), 7.18(2 \mathrm{H}, \mathrm{d}, J 9.1 \mathrm{~Hz}), 6.66(2 \mathrm{H}, \mathrm{d}, J 8.9 \mathrm{~Hz}), 3.85(2 \mathrm{H}, \mathrm{t}, J 5.9 \mathrm{~Hz}), 3.47(3 \mathrm{H}, \mathrm{s}), 2.23(2 \mathrm{H}, \mathrm{dd}, J 8.1,6.5$ $\mathrm{Hz}), 1.99-1.87(2 \mathrm{H}, \mathrm{m}) .{ }^{13} \mathrm{C}$ NMR $\left(75 \mathrm{MHz}, \mathrm{CDCl}_{3}\right): \delta_{\mathrm{C}} 168.7,157.2,130.7,130.3,129.2,128.8,128.7,125.5$, $118.2,115.6,91.9,66.1,58.1,27.7,23.8$. The enol ether $(0.55 \mathrm{~g}, 1.68 \mathrm{mmol})$ was treated with free guanidine $(0.32 \mathrm{~g}, 3.36 \mathrm{mmol})$ in dry DMSO $(5.0 \mathrm{ml})$ as described to afford 6a as a yellow solid $(0.065 \mathrm{~g}, 11 \%) . \mathrm{mp} \mathrm{130-}$ $132{ }^{\circ} \mathrm{C}$. IR $\left(v_{\max } / \mathrm{cm}^{-1}\right): 3328,3140,2929,1637,1583,1555 .{ }^{1} \mathrm{H}$ NMR $\left(300 \mathrm{MHz} \mathrm{CDCl}_{3}\right): \delta_{\mathrm{H}} 7.43-7.33(5 \mathrm{H}, \mathrm{m})$, $7.21(2 \mathrm{H}, \mathrm{d}, J 8.9 \mathrm{~Hz}), 6.74(2 \mathrm{H}, \mathrm{d}, J 8.9 \mathrm{~Hz}), 5.29(2 \mathrm{H}, \mathrm{s}), 5.15(2 \mathrm{H}, \mathrm{s}), 3.84(2 \mathrm{H}, \mathrm{t}, J 5.6 \mathrm{~Hz}), 2.53(2 \mathrm{H}, \mathrm{t}, J 8.6 \mathrm{~Hz})$, 1.93-1.84 (2H, m). ${ }^{13} \mathrm{C} \mathrm{NMR}\left(75 \mathrm{MHz}, \mathrm{CDCl}_{3}\right): \delta_{\mathrm{C}} 165.6,163.3,160.4,157.1,129.7,129.4,128.4,128.3,128.0$, 125.9, 115.7, 104.8, 67.1, 28.6, 22.2. HRMS (ESI): found [M + H] ${ }^{+} 355.1326, \mathrm{C}_{19} \mathrm{H}_{20}{ }^{35} \mathrm{CIN}_{4} \mathrm{O}$ requires 355.1327.

\section{5-(3-(3,4-Dichlorophenoxy)propyl)-6-phenylpyrimidine-2,4-diamine 2-Benzoyl-5-(3,4-}

dichlorophenoxy)pentanenitrile (11b) $(499 \mathrm{mg}, 1.38 \mathrm{mmol}$ ) was treated with diazomethane as described. The resulting enol ether was treated with free guanidine $(0.26 \mathrm{~g}, 2.76 \mathrm{mmol})$ in dry DMSO $(5.0 \mathrm{ml})$ to afford a lightyellow solid $(0.057 \mathrm{~g}, 11 \%) . \mathrm{mp} 102-104{ }^{\circ} \mathrm{C}$. IR $\left(v_{\max } / \mathrm{cm}^{-1}\right): 3430,3164,2866,1636,1582,1554 .{ }^{1} \mathrm{H}$ NMR (500 $\mathrm{MHz}, \mathrm{MeOD}): \delta_{\mathrm{H}} 7.52-7.35(5 \mathrm{H}, \mathrm{m}), 6.97(1 \mathrm{H}, \mathrm{t}, J 1.8 \mathrm{~Hz}), 6.65(2 \mathrm{H}, \mathrm{d}, J 1.8 \mathrm{~Hz}), 3.81(2 \mathrm{H}, \mathrm{t}, J 5.7 \mathrm{~Hz}), 2.60(2 \mathrm{H}$, $\mathrm{t}, \mathrm{J} 7.4 \mathrm{~Hz}), 1.91-1.83(2 \mathrm{H}, \mathrm{m}) .{ }^{13} \mathrm{C} N M R(126 \mathrm{MHz}, \mathrm{MeOD}): \delta_{\mathrm{C}} 171.6,165.1,160.0(2 \mathrm{C}), 135.0(2 \mathrm{C}), 129.7,128.5$, 128.1, $120.2(2 \mathrm{C}), 116.7,113.2,105.9,66.7,27.0,20.9$. HRMS (ESI): found $[\mathrm{M}+\mathrm{H}]^{+} 389.0936, \mathrm{C}_{19} \mathrm{H}_{19}{ }^{35} \mathrm{Cl}_{2} \mathrm{~N}_{4} \mathrm{O}$ requires 389.0938 .

\section{5-(3-(3,5-Dichlorophenoxy)propyl)-6-phenylpyrimidine-2,4-diamine}

(6c).

2-Benzoyl-5-(3,5dichlorophenoxy)pentanenitrile (11c) $(607 \mathrm{mg}, 1.68 \mathrm{mmol})$ was treated with diazomethane as described. The resulting enol ether was treated with free guanidine $(0.32 \mathrm{~g}, 3.36 \mathrm{mmol})$ in dry DMSO $(5.0 \mathrm{ml})$ to afford a brown solid $(0.048 \mathrm{~g}, 9 \%)$. $\mathrm{mp} 105-107^{\circ} \mathrm{C}$. IR $\left(v_{\mathrm{max}} / \mathrm{cm}^{-1}\right): 3430,3164,2956,1637,1599,1575 .{ }^{1} \mathrm{H} \mathrm{NMR}(300$ $\mathrm{MHz}, \mathrm{MeOD}): \delta_{\mathrm{H}} 7.98(2 \mathrm{H}, \mathrm{d}, J 7.5 \mathrm{~Hz}), 7.56-7.30(5 \mathrm{H}, \mathrm{m}), 6.98(1 \mathrm{H}, \mathrm{t}, J 1.8 \mathrm{~Hz}), 6.68(2 \mathrm{H}, \mathrm{d}, J 1.8 \mathrm{~Hz}), 3.83(2 \mathrm{H}$, $\mathrm{t}, J 5.8 \mathrm{~Hz}), 2.60(2 \mathrm{H}, \mathrm{t}, J 7.4 \mathrm{~Hz}), 1.98-1.72(2 \mathrm{H}, \mathrm{m}) .{ }^{13} \mathrm{C} N M R(126 \mathrm{MHz}, \mathrm{MeOD}): \delta_{\mathrm{C}} 164.7,159.9,157.7,135.0$, 130.8, 129.1, 128.2, 128.1, 127.5, 120.2, 113.2, 105.3, 66.9, 27.2, 21.1. HRMS (ESI): found [M + H] ${ }^{+} 389.0936$, $\mathrm{C}_{19} \mathrm{H}_{19}{ }^{35} \mathrm{Cl}_{2} \mathrm{~N}_{4} \mathrm{O}$ requires 389.0938 .

\section{5-(3-(3-Fluorophenoxy)propyl)-6-phenylpyrimidine-2,4-diamine}

(6d).

2-Benzoyl-5-(3fluorophenoxy)pentanenitrile (11d) $(450 \mathrm{mg}, 1.45 \mathrm{mmol})$ was treated with diazomethane as described. The resulting enol ether was treated with free guanidine $(0.28 \mathrm{~g}, 2.89 \mathrm{mmol})$ in dry DMSO $(5.0 \mathrm{ml})$ to afford a creamy-white solid $(0.043 \mathrm{~g}, 9 \%) . \mathrm{mp} 104-105^{\circ} \mathrm{C}$. IR $\left(v_{\max } / \mathrm{cm}^{-1}\right): 3479,3112,2875,1612,1576,1505 .{ }^{1} \mathrm{H}$ NMR 
(300 MHz, MeOD): $\delta_{H}$ 7.57-7.33 (4H, m), 7.29-7.09 (1H, m), 6.73-6.29 (3H, m), 3.82 (2H, t, J $\left.5.9 \mathrm{~Hz}\right), 2.56(2 \mathrm{H}$, dd, J 8.6, 6.6 Hz), 1.99-1.83 (2H, m). ${ }^{13} \mathrm{C} \mathrm{NMR}\left(75 \mathrm{MHz}, \mathrm{CDCl}_{3}\right): \delta_{\mathrm{C}} 175.04,163.7\left(\mathrm{~d}, J_{\mathrm{C}-\mathrm{F}} 245.0 \mathrm{~Hz}\right), 163.4,160.6$, $160.3\left(d, J_{C-F} 10.9 \mathrm{~Hz}\right), 130.24,130.1,128.3,128.29,128.0,110.3\left(\mathrm{~d}, J_{C-F} 3.0 \mathrm{~Hz}\right), 107.4\left(\mathrm{~d}, J_{\mathrm{C}-\mathrm{F}} 21.3 \mathrm{~Hz}\right), 104.7$, $102.2\left(d, J_{C-F} 24.7 \mathrm{~Hz}\right), 67.8,28.6,22.1$. HRMS (ESI) found [M + H] ${ }^{+} 339.1621, \mathrm{C}_{19} \mathrm{H}_{20} \mathrm{FN}_{4} \mathrm{O}$ requires 339.1703.

General procedure for the synthesis of (4-bromopropoxy)benzenes (12). (4-Bromopropoxy)benzenes (12) were prepared using the same method described for the synthesis of (4-bromobutoxy)benzenes 9 described above.

1-(3-Bromopropoxy)-4-chlorobenzene (12a). ${ }^{9}$ Prepared from 4-chlorophenol (8a) (6.50 g, $\left.50.6 \mathrm{mmol}\right)$, 1,3dibromopropane $(15.4 \mathrm{ml}, 152 \mathrm{mmol})$ and potassium carbonate $(10.5 \mathrm{~g}, 75.8 \mathrm{mmol})$ in dry acetonitrile (300 $\mathrm{ml})$, isolated as a white crystalline solid $(12.5 \mathrm{~g}, 99 \%) . \mathrm{mp} \mathrm{28-29}{ }^{\circ} \mathrm{C} . \mathrm{IR}\left(v_{\max } / \mathrm{cm}^{-1}\right): 2959,1596,1578,1102$. ${ }^{1} \mathrm{H}$ NMR $\left(300 \mathrm{MHz}, \mathrm{CDCl}_{3}\right): \delta_{\mathrm{H}} 7.23(2 \mathrm{H}, \mathrm{d}, J 8.9 \mathrm{~Hz}), 6.81(2 \mathrm{H}, \mathrm{d}, J 8.9 \mathrm{~Hz}), 4.02(2 \mathrm{H}, \mathrm{t}, J 5.7 \mathrm{~Hz}), 3.46(2 \mathrm{H}, \mathrm{t}, J 6.5$ $\mathrm{Hz}), 2.19-1.95(2 \mathrm{H}, \mathrm{m}) .{ }^{13} \mathrm{C} \mathrm{NMR}\left(75 \mathrm{MHz}, \mathrm{CDCl}_{3}\right): \delta_{\mathrm{C}} 157.3,129.3,125.6,115.7,67.2,33.3,27.8$.

4-(3-Bromopropoxy)-1,2-dichlorobenzene (12b). ${ }^{9}$ Prepared from 3,4-dichlorophenol (8b) (5.40 g, $\left.33.1 \mathrm{mmol}\right)$, 1,3-dibromopropane $(10.1 \mathrm{ml}, 99.4 \mathrm{mmol})$ and potassium carbonate $(6.87 \mathrm{~g}, 49.7 \mathrm{mmol})$ in dry acetonitrile $(250 \mathrm{ml})$, isolated as a white solid $(8.96 \mathrm{~g}, 95 \%) . \mathrm{mp} \mathrm{29-30}{ }^{\circ} \mathrm{C} . \mathrm{IR}\left(v_{\mathrm{max}} / \mathrm{cm}^{-1}\right): 3041,1578,1145 .{ }^{1} \mathrm{H} \mathrm{NMR}(300$ $\left.\mathrm{MHz}, \mathrm{CDCl}_{3}\right): \delta_{\mathrm{H}} 7.31(1 \mathrm{H}, \mathrm{d}, J 8.9 \mathrm{~Hz}), 6.97(1 \mathrm{H}, \mathrm{d}, J 2.9 \mathrm{~Hz}), 6.73(1 \mathrm{H}, \mathrm{dd}, J$ 8.9, $2.9 \mathrm{~Hz}), 4.00(2 \mathrm{H}, \mathrm{t}, J 5.8 \mathrm{~Hz})$, $3.45(2 \mathrm{H}, \mathrm{t}, J 6.4 \mathrm{~Hz}), 2.18-1.99(2 \mathrm{H}, \mathrm{m}) .{ }^{13} \mathrm{C} \mathrm{NMR}\left(75 \mathrm{MHz}, \mathrm{CDCl}_{3}\right): \delta_{\mathrm{C}} 157.4,132.7,130.7,124.2,116.4,114.5$, $66.0,25.2,14.1$.

1-(3-Bromopropoxy)-3,5-dichlorobenzene (12c). ${ }^{9}$ Prepared from 3,5-dichlorophenol (8c) (5.00 g, $\left.30.7 \mathrm{mmol}\right)$, 1,3-dibromopropane $(9.34 \mathrm{ml}, 92.0 \mathrm{mmol})$ and potassium carbonate $(6.36 \mathrm{~g}, 46.0 \mathrm{mmol})$ in dry acetonitrile $(200 \mathrm{ml})$, isolated as a white solid $(8.46 \mathrm{~g}, 97 \%) . \mathrm{mp} 27-28{ }^{\circ} \mathrm{C} . \mathrm{IR}\left(v_{\max } / \mathrm{cm}^{-1}\right): 2953,1581,1576,1141 .{ }^{1} \mathrm{H}$ NMR $\left(300 \mathrm{MHz}, \mathrm{CDCl}_{3}\right): \delta_{\mathrm{H}} 6.91(1 \mathrm{H}, \mathrm{t}, J 1.8 \mathrm{~Hz}), 6.75(2 \mathrm{H}, \mathrm{d}, J 1.9 \mathrm{~Hz}), 3.92(2 \mathrm{H}, \mathrm{t}, J 5.9 \mathrm{~Hz}), 3.45(2 \mathrm{H}, \mathrm{t}, J 6.4 \mathrm{~Hz})$, 1.90-1.77 (2H, m). ${ }^{13} \mathrm{C} N M R\left(75 \mathrm{MHz}, \mathrm{CDCl}_{3}\right): \delta_{\mathrm{C}} 159.7,135.5(2 \mathrm{C}), 121.3,114.0(2 \mathrm{C}), 67.3,28.0,22.3$.

1-(3-Bromopropoxy)-4-fluorobenzene (12d). ${ }^{15}$ Prepared from 4-fluorophenol (8f) (4.00 g, $\left.35.7 \mathrm{mmol}\right)$, 1,3dibromopropane $(10.9 \mathrm{ml}, 107 \mathrm{mmol})$ and potassium carbonate $(7.40 \mathrm{~g}, 53.5 \mathrm{mmol})$ in dry acetonitrile (200 $\mathrm{ml}$ ), isolated as a pale solid (7.26 g, 87\%). $\mathrm{mp} \mathrm{30-31}{ }^{\circ} \mathrm{C}$. IR $\left(v_{\mathrm{max}} / \mathrm{cm}^{-1}\right): 2956,1593,1577,1084 .{ }^{1} \mathrm{H}$ NMR (300 $\left.\mathrm{MHz}, \mathrm{CDCl}_{3}\right): \delta_{\mathrm{H}} 7.08-6.94(2 \mathrm{H}, \mathrm{m}), 6.85-6.81(2 \mathrm{H}, \mathrm{m}), 4.02(2 \mathrm{H}, \mathrm{t}, J 5.6 \mathrm{~Hz}), 3.45(2 \mathrm{H}, \mathrm{t}, J 6.4 \mathrm{~Hz}), 2.15-2.07(2 \mathrm{H}$, m). ${ }^{13} \mathrm{C} \mathrm{NMR}\left(75 \mathrm{MHz}, \mathrm{CDCl}_{3}\right): \delta_{\mathrm{C}} 157.3\left(\mathrm{~d}, J_{\mathrm{C}-\mathrm{F}} 238.3 \mathrm{~Hz}\right), 154.9\left(\mathrm{~d}, J_{\mathrm{C}-\mathrm{F}} 2.0 \mathrm{~Hz}\right), 115.8\left(\mathrm{~d}, J_{\mathrm{C}-\mathrm{F}} 23.1 \mathrm{~Hz}\right), 115.4(\mathrm{~d}$, $\left.J_{C-F} 8.0 \mathrm{~Hz}\right), 66.0,30.8,14.2$.

General procedure for the synthesis of 6-(4-(4-chlorophenoxy)butoxy)pyrimidine-2,4-diamine (7a) and analogues. To a stirred solution of 2,4-diamino-6-hydroxy pyrimidine in dry acetonitrile (20 ml) was added potassium carbonate $(1.5 \mathrm{eq})$, followed by a suitably substituted bromoether 9 or 12 (1.0 eq) in dry acetonitrile $(30 \mathrm{ml})$. The reaction was heated to reflux under an atmosphere of nitrogen overnight. The reaction mixture was allowed to cool to room temperature, filtered through celite and the filtrate was concentrated in vacuo. The crude product was purified by column chromatography (EtOAc/hexane 60:40) to furnish the desired product.

6-(4-(4-Chlorophenoxy)butoxy)pyrimidine-2,4-diamine (7a). Prepared from 2,4-diamino-6-hydroxy pyrimidine $(0.48 \mathrm{~g}, 3.79 \mathrm{mmol})$, potassium carbonate $(0.79 \mathrm{~g}, 5.69 \mathrm{mmol})$ and $9 \mathrm{a}(1.00 \mathrm{~g}, 3.79 \mathrm{mmol})$ in dry acetonitrile, isolated as a white solid $(0.58 \mathrm{~g}, 50 \%) \cdot \mathrm{mp} 97-98^{\circ} \mathrm{C}$. IR $\left(v_{\max } / \mathrm{cm}^{-1}\right): 3520,3359,3011,1576,1124$, 791. ${ }^{1} \mathrm{H}$ NMR $\left(300 \mathrm{MHz}\right.$, DMSO- $\left.d_{6}\right): \delta_{\mathrm{H}} 7.31(2 \mathrm{H}, \mathrm{d}, J 8.9 \mathrm{~Hz}), 6.95(2 \mathrm{H}, \mathrm{d}, J 9.0 \mathrm{~Hz}), 5.98(2 \mathrm{H}, \mathrm{s}), 5.82(2 \mathrm{H}, \mathrm{s}), 5.04$ $(1 \mathrm{H}, \mathrm{s}), 4.15-4.11(2 \mathrm{H}, \mathrm{m}), 3.98(2 \mathrm{H}, \mathrm{t}, J 3.5 \mathrm{~Hz}), 1.81-1.68(4 \mathrm{H}, \mathrm{m}) .{ }^{13} \mathrm{C}$ NMR $\left(75 \mathrm{MHz}, \mathrm{DMSO}-d_{6}\right): \delta_{\mathrm{C}} 170.1$, 
165.9, 162.9, 157.4, 129.2, 124.1, 116.2, 76.1, 67.5, 64.1, 25.3 (2C). HRMS (ESI): found [M + H] 309.1117, $\mathrm{C}_{14} \mathrm{H}_{18} \mathrm{ClN}_{4} \mathrm{O}_{2}$ requires 309.1120 .

6-(4-(3,4-Dichlorophenoxy)butoxy)pyrimidine-2,4-diamine (7b). Prepared from 2,4-diamino-6-hydroxy pyrimidine $(0.43 \mathrm{~g}, 3.42 \mathrm{mmol})$, potassium carbonate $(0.71 \mathrm{~g}, 5.13 \mathrm{mmol})$ and $9 \mathrm{~b}(1.02 \mathrm{~g}, 3.42 \mathrm{mmol})$ in dry acetonitrile, isolated as a white solid $(0.53 \mathrm{~g}, 45 \%) . \mathrm{mp} 136-137{ }^{\circ} \mathrm{C} . \mathrm{IR}\left(v_{\max } / \mathrm{cm}^{-1}\right): 3520,3359,3011,1576$, 1124, 791. ${ }^{1} \mathrm{H}$ NMR $(300 \mathrm{MHz} \text {, DMSO-d })_{6}: \delta_{\mathrm{H}} 7.50(1 \mathrm{H}, \mathrm{d}, J 8.9 \mathrm{~Hz}), 7.22(1 \mathrm{H}, \mathrm{d}, J 2.9 \mathrm{~Hz}), 6.95(1 \mathrm{H}, \mathrm{dd}, J 8.9,2.9$ $\mathrm{Hz}), 5.99(2 \mathrm{H}, \mathrm{s}), 5.82(2 \mathrm{H}, \mathrm{s}), 5.04(1 \mathrm{H}, \mathrm{s}), 4.15-4.11(2 \mathrm{H}, \mathrm{m}), 4.05-4.01(2 \mathrm{H}, \mathrm{m}), 1.78-1.74(4 \mathrm{H}, \mathrm{m}) .{ }^{13} \mathrm{C} \mathrm{NMR}(75$ $\left.\mathrm{MHz}, \mathrm{DMSO}-d_{6}\right): \delta_{\mathrm{C}} 170.6,166.5,163.4,158.6,132.1,131.4,122.7,116.8,115.9,76.6,68.5,64.6,25.7$ (2C). HRMS (ESI): found [M + H] $]^{+} 343.0729, \mathrm{C}_{14} \mathrm{H}_{17} \mathrm{Cl}_{2} \mathrm{~N}_{4} \mathrm{O}_{2}$ requires 343.0730 .

6-(4-(3,5-Dichlorophenoxy)butoxy)pyrimidine-2,4-diamine (7c). Prepared from 2,4-diamino-6-hydroxy pyrimidine $(0.40 \mathrm{~g}, 3.15 \mathrm{mmol})$, potassium carbonate $(0.65 \mathrm{~g}, 4.73 \mathrm{mmol})$ and $9 \mathrm{c}(0.94 \mathrm{~g}, 3.15 \mathrm{mmol})$ in dry acetonitrile, isolated as a white solid $(0.59 \mathrm{~g}, 55 \%) . \mathrm{mp} 106-107{ }^{\circ} \mathrm{C}$. IR $\left(v_{\mathrm{max}} / \mathrm{cm}^{-1}\right): 3440,3327,3008,1560$, 1141, 828, 791. ${ }^{1} \mathrm{H}$ NMR $\left(300 \mathrm{MHz}, \mathrm{DMSO}-d_{6}\right): \delta_{\mathrm{H}} 7.13(1 \mathrm{H}, \mathrm{t}, J 1.8 \mathrm{~Hz}), 7.03(2 \mathrm{H}, \mathrm{d}, J 1.8 \mathrm{~Hz}), 5.98(2 \mathrm{H}, \mathrm{s}), 5.82$ $(2 \mathrm{H}, \mathrm{s}), 5.04(1 \mathrm{H}, \mathrm{s}), 4.15-4.10(2 \mathrm{H}, \mathrm{m}), 4.06-4.00(2 \mathrm{H}, \mathrm{m}), 1.83-1.68(4 \mathrm{H}, \mathrm{m}) .{ }^{13} \mathrm{C}$ NMR $\left(75 \mathrm{MHz}, \mathrm{DMSO}-d_{6}\right): \delta_{\mathrm{c}}$ 170.1, 165.9, 163.0, 160.1, 134.5 (2C), 120.1, 113.8 (2C), 76.1, 68.2, 25.2, 25.1, HRMS (ESI): found [M + H] 343.0724, $\mathrm{C}_{14} \mathrm{H}_{17} \mathrm{Cl}_{2} \mathrm{~N}_{4} \mathrm{O}_{2}$ requires 343.0730 .

6-(4-(3-fluorophenoxy)butoxy)pyrimidine-2,4-diamine (7d). Prepared from 2,4-diamino-6-hydroxy pyrimidine $(0.27 \mathrm{~g}, 2.14 \mathrm{mmol})$, potassium carbonate $(0.44 \mathrm{~g}, 3.22 \mathrm{mmol})$ and $9 \mathrm{~d}(0.53 \mathrm{~g}, 2.14 \mathrm{mmol})$ in dry acetonitrile, isolated as an off-white solid $(0.25 \mathrm{~g}, 40 \%) \cdot \mathrm{mp} 98-99^{\circ} \mathrm{C}$. IR $\left(v_{\max } / \mathrm{cm}^{-1}\right): 3512,3344,2939,1569,1145,1016 .{ }^{1} \mathrm{H}$ NMR $\left(300 \mathrm{MHz}, \mathrm{DMSO}-d_{6}\right): \delta_{\mathrm{H}} 7.34-7.26(1 \mathrm{H}, \mathrm{m}), 6.83-6.71(3 \mathrm{H}, \mathrm{m}), 6.02(2 \mathrm{H}, \mathrm{s}), 5.86(2 \mathrm{H}, \mathrm{s}), 5.04(1 \mathrm{H}, \mathrm{s}), 4.15$ $(2 \mathrm{H}, \mathrm{t}, J 6.0 \mathrm{~Hz}), 4.01(2 \mathrm{H}, \mathrm{t}, J 3.7 \mathrm{~Hz}), 1.79-1.77(4 \mathrm{H}, \mathrm{m}) .{ }^{13} \mathrm{C} N M R\left(75 \mathrm{MHz}, \mathrm{DMSO}-d_{6}\right): \delta_{\mathrm{C}} 170.1,165.9,163.0$ $\left(d, J_{C-F} 245.3 \mathrm{~Hz}\right), 162.8,160.1\left(\mathrm{~d}, J_{\mathrm{C}-\mathrm{F}} 10.8 \mathrm{~Hz}\right), 130.6\left(\mathrm{~d}, J_{\mathrm{C}-\mathrm{F}} 10.0 \mathrm{~Hz}\right), 110.8$ (d, $\left.J_{\mathrm{C}-\mathrm{F}} 2.9 \mathrm{~Hz}\right), 106.9$ (d, $J_{\mathrm{C}-\mathrm{F}} 21.3$ $\mathrm{Hz}$ ), 101.9 (d, $J_{\mathrm{C}-\mathrm{F}} 24.8 \mathrm{~Hz}$ ), 76.1, 67.6, 64.2, 25.33, 25.31. HRMS (ESI): found [M + H] ${ }^{+} 293.1413, \mathrm{C}_{14} \mathrm{H}_{18} \mathrm{FN}_{4} \mathrm{O}_{2}$ requires 293.1416.

6-(4-(4-Fluorophenoxy)butoxy)pyrimidine-2,4-diamine (7e). Prepared from 2,4-diamino-6-hydroxy pyrimidine $(0.23 \mathrm{~g}, 1.86 \mathrm{mmol})$, potassium carbonate $(0.39 \mathrm{~g}, 2.79 \mathrm{mmol})$ and $9 \mathrm{e}(0.46 \mathrm{~g}, 1.86 \mathrm{mmol})$ in dry acetonitrile, isolated as a white solid $(0.18 \mathrm{~g}, 33 \%) \cdot \mathrm{mp} 138-139{ }^{\circ} \mathrm{C} . \mathrm{IR}\left(v_{\max } / \mathrm{cm}^{-1}\right): 3478,2957,1577,1216,1199,1075 .{ }^{1} \mathrm{H}$ NMR $\left(300 \mathrm{MHz}, \mathrm{DMSO}-d_{6}\right): \delta_{\mathrm{H}} 7.12-7.06(2 \mathrm{H}, \mathrm{m}), 6.99-6.84(2 \mathrm{H}, \mathrm{m}), 5.99(2 \mathrm{H}, \mathrm{s}), 5.81(2 \mathrm{H}, \mathrm{s}), 5.06(1 \mathrm{H}, \mathrm{s}), 4.13$ $(2 \mathrm{H}, \mathrm{t}, J 3.1 \mathrm{~Hz}), 3.98-3.94(2 \mathrm{H}, \mathrm{m}), 1.78-1.74(4 \mathrm{H}, \mathrm{m}) .{ }^{13} \mathrm{C} N M R\left(75 \mathrm{MHz}, \mathrm{DMSO}-d_{6}\right): \delta_{\mathrm{C}} 170.1,165.9,162.9$, $156.4\left(\mathrm{~d}, J_{\mathrm{C}-\mathrm{F}} 227.9 \mathrm{~Hz}\right.$ ), 154.8 (d, $J_{\mathrm{C}-\mathrm{F}} 2.0 \mathrm{~Hz}$ ), 115.8 (d, $J_{\mathrm{C}-\mathrm{F}} 23.1 \mathrm{~Hz}$ ), 115.6 (d, $J_{\mathrm{C}-\mathrm{F}} 8.0 \mathrm{~Hz}$ ), 76.1, 67.7, 64.2, 25.4, 25.3. HRMS (ESI): found $[\mathrm{M}+\mathrm{H}]^{+} 293.1411, \mathrm{C}_{14} \mathrm{H}_{18} \mathrm{FN}_{4} \mathrm{O}_{2}$ requires 293.1416.

6-(4-(3-(Trifluoromethyl)phenoxy)butoxy)pyrimidine-2,4-diamine (7f). Prepared from 2,4-diamino-6-hydroxy pyrimidine $(0.51 \mathrm{~g}, 4.04 \mathrm{mmol})$, potassium carbonate $(0.84 \mathrm{~g}, 6.06 \mathrm{mmol})$ and $9 \mathrm{f}(1.20 \mathrm{~g}, 4.04 \mathrm{mmol})$ in dry acetonitrile, isolated as a white solid $(0.64 \mathrm{~g}, 46 \%) \mathrm{mp} 100-101{ }^{\circ} \mathrm{C}$. IR $\left(v_{\max } / \mathrm{cm}^{-1}\right): 3512,2939,1569,1216$, 1141, 1015. ${ }^{1} \mathrm{H}$ NMR $\left(500 \mathrm{MHz}, \mathrm{DMSO}-d_{6}\right): \delta_{\mathrm{H}} 7.35(1 \mathrm{H}, \mathrm{t}, J 8.0 \mathrm{~Hz}), 7.17(1 \mathrm{H}, \mathrm{d}, J 7.8 \mathrm{~Hz}), 7.11(1 \mathrm{H}, \mathrm{t}, J 2.1 \mathrm{~Hz})$, $7.04(1 \mathrm{H}, \mathrm{dd}, J$ 8.3, $2.5 \mathrm{~Hz}), 5.27-5.13(2 \mathrm{H}, \mathrm{m}), 4.97(2 \mathrm{H}, \mathrm{s}), 4.26-4.13(2 \mathrm{H}, \mathrm{m}), 4.00(2 \mathrm{H}, \mathrm{t}, J 3.8 \mathrm{~Hz}), 1.97-1.74$ $(4 \mathrm{H}, \mathrm{m}) .{ }^{13} \mathrm{C}$ NMR $\left(125 \mathrm{MHz}, \mathrm{DMSO}-d_{6}\right): \delta_{\mathrm{C}} 170.6,166.4,163.4,159.4,130.8(q, J 31.7 \mathrm{~Hz}), 124.5$ (q, J $J_{\mathrm{C}-\mathrm{F}} 272.4$ $\mathrm{Hz}), 119.2,117.4\left(q, J_{\mathrm{C}-\mathrm{F}}=3.8 \mathrm{~Hz}\right), 111.4(q, J 3.7 \mathrm{~Hz}), 76.6,68.2,64.6,25.8(2 \mathrm{C}) . \mathrm{HRMS}(\mathrm{ESI})$ : found [M + H] 343.1377, $\mathrm{C}_{15} \mathrm{H}_{18} \mathrm{~F}_{3} \mathrm{~N}_{4} \mathrm{O}_{2}$ requires 343.1384.

6-(3-(4-Chlorophenoxy)propoxy)pyrimidine-2,4-diamine (7g). Prepared from 2,4-diamino-6-hydroxy pyrimidine $(0.51 \mathrm{~g}, 4.01 \mathrm{mmol})$, potassium carbonate $(0.83 \mathrm{~g}, 6.01 \mathrm{mmol})$ and $12 \mathrm{a}(1.00 \mathrm{~g}, 4.01 \mathrm{mmol})$ in dry acetonitrile, isolated as a white solid $(0.41 \mathrm{~g}, 35 \%) \cdot \mathrm{mp} 81-82^{\circ} \mathrm{C} . \mathrm{IR}\left(v_{\max } / \mathrm{cm}^{-1}\right): 3520,3359,3011,1576,1125$, 791. ${ }^{1} \mathrm{H}$ NMR $\left(300 \mathrm{MHz}\right.$, DMSO- $\left.d_{6}\right): \delta_{\mathrm{H}} 7.31(2 \mathrm{H}, \mathrm{d}, J 9.0 \mathrm{~Hz}), 6.96(2 \mathrm{H}, \mathrm{d}, J 9.0 \mathrm{~Hz}), 6.00(2 \mathrm{H}, \mathrm{s}), 5.85(2 \mathrm{H}, \mathrm{s}), 5.06$ $(1 \mathrm{H}, \mathrm{s}), 4.22(2 \mathrm{H}, \mathrm{t}, J 6.4 \mathrm{~Hz}), 4.05(2 \mathrm{H}, \mathrm{t}, J 6.3 \mathrm{~Hz}), 2.07(2 \mathrm{H}, \mathrm{p}, J 6.3 \mathrm{~Hz}) .{ }^{13} \mathrm{C}$ NMR $\left(75 \mathrm{MHz}, \mathrm{DMSO}-d_{6}\right): \delta_{C} 170.0$, 
165.9, 163.0, 157.3, 129.3, 124.2, 116.2, 76.1, 64.8, 61.4, 28.5. HRMS (ESI): found [M + H] 295.0956, $\mathrm{C}_{13} \mathrm{H}_{16} \mathrm{CIN}_{4} \mathrm{O}_{2}$ requires 295.0964 .

6-(3-(3,4-Dichlorophenoxy)propoxy)pyrimidine-2,4-diamine (7h). Prepared from 2,4-diamino-6-hydroxy pyrimidine $(0.44 \mathrm{~g}, 3.52 \mathrm{mmol})$, potassium carbonate $(0.73 \mathrm{~g}, 5.28 \mathrm{mmol})$ and $12 \mathrm{~b}(1.00 \mathrm{~g}, 3.52 \mathrm{mmol})$ in dry acetonitrile, isolated as a light yellow solid (0.43 g, 37\%). $\mathrm{mp} 134-135{ }^{\circ} \mathrm{C}$. IR $\left(v_{\max } / \mathrm{cm}^{-1}\right): 3529,3343,3010$, 1581, 1101. ${ }^{1} \mathrm{H}$ NMR $\left(300 \mathrm{MHz}\right.$, DMSO- $\left.d_{6}\right): \delta_{\mathrm{H}} 7.50(1 \mathrm{H}, \mathrm{d}, J 8.9 \mathrm{~Hz}), 7.22(1 \mathrm{H}, \mathrm{d}, J 2.9 \mathrm{~Hz}), 6.95(1 \mathrm{H}, \mathrm{dd}, J 8.9$, $2.9 \mathrm{~Hz}), 5.99(2 \mathrm{H}, \mathrm{s}), 5.82(2 \mathrm{H}, \mathrm{s}), 5.04(1 \mathrm{H}, \mathrm{s}), 4.22(2 \mathrm{H}, \mathrm{t}, J 6.4 \mathrm{~Hz}), 4.12(2 \mathrm{H}, \mathrm{t}, J 6.2 \mathrm{~Hz}), 2.06(2 \mathrm{H}, \mathrm{p}, J 6.3 \mathrm{~Hz})$. ${ }^{13} \mathrm{C}$ NMR $\left(75 \mathrm{MHz}\right.$, DMSO- $\left.d_{6}\right): \delta_{H} 170.4,166.5,163.4,158.5,132.1,131.4,122.8,116.8,115.9,76.6,65.8,61.8$, 28.9. HRMS (ESI): found $[\mathrm{M}+\mathrm{H}]^{+} 329.0565, \mathrm{C}_{13} \mathrm{H}_{15} \mathrm{Cl}_{2} \mathrm{~N}_{4} \mathrm{O}_{2}$ requires 329.0574 .

6-(3-(3,5-Dichlorophenoxy)propoxy)pyrimidine-2,4-diamine (7i). Prepared from 2,4-diamino-6-hydroxy pyrimidine $(0.89 \mathrm{~g}, 7.04 \mathrm{mmol})$, potassium carbonate $(1.46 \mathrm{~g}, 10.6 \mathrm{mmol})$ and $12 \mathrm{c}(2.00 \mathrm{~g}, 7.04 \mathrm{mmol})$ in dry acetonitrile, isolated as a creamy white solid $(1.26 \mathrm{~g}, 54 \%) . \mathrm{mp} 105-107^{\circ} \mathrm{C}$. IR $\left(v_{\max } / \mathrm{cm}^{-1}\right): 3541,3362,3035$, 1588, 1144, 799. ${ }^{1} \mathrm{H}$ NMR $\left(300 \mathrm{MHz}, \mathrm{DMSO}-d_{6}\right): \delta_{\mathrm{H}} 7.14(1 \mathrm{H}, \mathrm{t}, J 1.8 \mathrm{~Hz}), 7.06(2 \mathrm{H}, \mathrm{d}, J 1.8 \mathrm{~Hz}), 6.00(2 \mathrm{H}, \mathrm{s}), 5.84$ $(2 \mathrm{H}, \mathrm{s}), 5.05(1 \mathrm{H}, \mathrm{s}), 4.21(2 \mathrm{H}, \mathrm{t}, J 6.4 \mathrm{~Hz}), 4.12(2 \mathrm{H}, \mathrm{t}, J 6.2 \mathrm{~Hz}), 2.11-2.02(2 \mathrm{H}, \mathrm{m}) .{ }^{13} \mathrm{C} \mathrm{NMR}\left(75 \mathrm{MHz}, \mathrm{DMSO}-d_{6}\right)$ : $\delta_{C} 170.0,166.0,163.0,160.0,134.6(2 \mathrm{C}), 120.3,113.9(2 \mathrm{C}), 76.1,65.5,61.2,28.3$, HRMS (ESI): found [M + H] $]^{+}$ $329.0572, \mathrm{C}_{13} \mathrm{H}_{15} \mathrm{Cl}_{2} \mathrm{~N}_{4} \mathrm{O}_{2}$ requires 329.0574 .

6-(3-(4-Fluorophenoxy)propoxy)pyrimidine-2,4-diamine (7j). Prepared from 2,4-diamino-6-hydroxy pyrimidine $(0.27 \mathrm{~g}, 2.15 \mathrm{mmol})$, potassium carbonate $(0.44 \mathrm{~g}, 3.22 \mathrm{mmol})$ and compound $12 \mathrm{~d}(0.50 \mathrm{~g}, 2.15$ $\mathrm{mmol})$ in dry acetonitrile, isolated as a white solid $(0.20 \mathrm{~g}, 34 \%) . \mathrm{mp} 69-71^{\circ} \mathrm{C}$. IR $\left(v_{\mathrm{max}} / \mathrm{cm}^{-1}\right): 3539,3332,3032$, 1586, 1153. ${ }^{1} \mathrm{H}$ NMR $\left(300 \mathrm{MHz}, \mathrm{DMSO}-d_{6}\right): \delta_{\mathrm{H}} 7.18-7.01(2 \mathrm{H}, \mathrm{m}), 6.99-6.87(2 \mathrm{H}, \mathrm{m}), 5.99(2 \mathrm{H}, \mathrm{s}), 5.85(2 \mathrm{H}, \mathrm{s})$, $5.04(1 \mathrm{H}, \mathrm{s}), 4.22(2 \mathrm{H}, \mathrm{t}, J 6.3 \mathrm{~Hz}), 4.03(2 \mathrm{H}, \mathrm{t}, J 6.3 \mathrm{~Hz}), 2.06(2 \mathrm{H}, \mathrm{p}, J 6.3 \mathrm{~Hz}) .{ }^{13} \mathrm{C} \mathrm{NMR}\left(75 \mathrm{MHz}, \mathrm{DMSO}-d_{6}\right): \delta_{c}$ 170.0, 166.0, 163.0, 159.7 (d, $J_{C-F} 225.5 \mathrm{~Hz}$ ), 154.8 (d, $J_{\mathrm{C}-\mathrm{F}} 3.0 \mathrm{~Hz}$ ), 115.8 (d, $\left.J_{\mathrm{C}-\mathrm{F}} 15.7 \mathrm{~Hz}\right), 115.6,76.1,65.0$, 61.4, 28.6. HRMS (ESI): found $[\mathrm{M}+\mathrm{H}]^{+}$279.1252, $\mathrm{C}_{13} \mathrm{H}_{16} \mathrm{FN}_{4} \mathrm{O}_{2}$ requires 279.1310 .

\section{Biology}

\section{SYBR green assay against Gambian FCR-3 strain}

P. falciparum (FCR-3) strain was cultured in vitro at $37{ }^{\circ} \mathrm{C}$ in $3 \% \mathrm{O}_{2}, 5 \% \mathrm{CO}_{2}, 92 \% \mathrm{~N}_{2}$ and adjusted to a $0.625 \%$ parasitaemia/1.25\% haematocrit before being incubated along with the analogues for $72 \mathrm{~h}$. The plates were frozen overnight and, once thawed, incubated in the dark for $1 \mathrm{~h}$ at room temperature with buffered SYBR green I. The fluorescence was read in a microplate reader with excitation and emission wavelength bands centred at 485 and $528 \mathrm{~nm}$, respectively. The percentage inhibition was calculated taking the untreated and dihydroartemisinin control into account. Dihydroartemisinin (DHA) and methotrexate (MTX) were used as positive controls. At least three independent experiments were conducted for each analogue. The concentration that inhibited $50 \%$ of parasite growth ( $\mathrm{IC}_{50}$ value) was determined from the log sigmoid dose response curves generated by GraphPad Prism ${ }^{\circledR}$ software. Each experiment was repeated in triplicate.

\section{Acknowledgements}

Research reported in this publication was supported by the Medical Research Council (South Africa) under a Self-Initiated Research Grant. HFK and TDS thank the National Research Foundation (South Africa) for funding. 


\section{Supplementary Material}

Readers will be able to access supporting information $\left({ }^{1} \mathrm{H}\right.$ and ${ }^{13} \mathrm{C}$ NMR spectra of synthesized compounds) using the link "Supplementary Material" in the journal issue contents.

\section{References}

1. WHO, World Malaria Report 2019. 2019.

https://www.who.int/publications/i/item/world-malaria-report-2019

2. Salcedo-Sora, J. E.; Ward, S. A. Mol. Biochem. Parasitol. 2013, 188, 51-62.

https://doi.org/10.1016/i.molbiopara.2013.02.003

3. Nzila, A. J. Antimicrob. Chemother. 2006, 57, 1043-1054.

https://doi.org/10.1093/jac/dkl104

4. Mita, T.; Tanabe, K.; Kita, K. Parasitol. Int. 2009, 58, 201-209.

https://doi.org/10.1016/j.parint.2009.04.004

5. Heinberg, A.; Kirkman, L. Ann. N. Y. Acad. Sci. 2015, 1342, 10-18.

http://dx.doi.org/10.1111/nyas.12662

6. Rastelli, G.; Sirawaraporn, W.; Sompornpisut, P.; Vilaivan, T.; Kamchonwongpaisan, S.; Quarrell, R.; Lowe, G.; Thebtaranonth, Y.; Yuthavong, Y. Bioorg. Med. Chem. 2000, 8, 1117-1128.

https://doi.org/10.1016/S0968-0896(00)00022-5

7. Yuthavong, Y.; Tarnchompoo, B.; Vilaivan, T.; Chitnumsub, P.; Kamchonwongpaisan, S.; Charman, S. A.; McLennan, D. N.; White, K. L.; Vivas, L.; Bongard, E.; Thongphanchang, C.; Taweechai, S.; Vanichtanankul, J.; Rattanajak, R.; Arwon, U.; Fantauzzi, P.; Yuvaniyama, J.; Charman, W. N.; Matthews, D. PNAS 2012, 109, 16823-16828.

https://doi.org/10.1073/pnas.1204556109

8. Lourens, A. C. U.; Gravestock, D.; van Zyl, R. L.; Hoppe, H. C.; Kolesnikova, N.; Taweechai, S.; Yuthavong, Y.; Kamchonwongpaisan, S.; Rousseau, A. L. Org. Biomol. Chem. 2016, 14, 7899-7911.

http://dx.doi.org/10.1039/C6OB01350C

9. Gravestock, D.; Rousseau, A. L.; Lourens, A. C. U.; Moleele, S. S.; van Zyl, R. L.; Steenkamp, P. A. Eur. J. Med. Chem. 2011, 46, 2022-2030.

https://doi.org/10.1016/i.ejmech.2011.02.054

10. Russell, P. B.; Hitchings, G. H. J. Am. Chem. Soc. 1951, 73, 3763-3770.

http://dx.doi.org/10.1021/ja01152a060

11. Docking studies were carried out with Biovia Discovery Studio 2.0, using CDocker. The DHFR-TS receptors were obtained from the RCSB PDB: 1J3I (WT) and 1J3K (quadruple mutant) complexed with WR99210, NADPH and dUMP (at the thymidylate synthase (TS) site).

12. Thompson, M.; Carkner, C.; Mosey, N. J.; Kapernaum, N.; Lemieux, R. P. Soft Matter 2015, 11, 3860-3868. http://dx.doi.org/10.1039/C5SM00473J

13. Wang, S.; Wang, Y.; Liu, W.; Liu, N.; Zhang, Y.; Dong, G.; Liu, Y.; Li, Z.; He, X.; Miao, Z.; Yao, J.; Li, J.; Zhang, W.; Sheng, C. ACS Med. Chem. Lett. 2014, 5, 506-511.

https://doi.org/10.1021/ml400492t

14. Schmitz, A.; Sankaranarayanan, A.; Azam, P.; Schmidt-Lassen, K.; Homerick, D.; Hänsel, W.; Wulff, H. Mol. Pharmacol. 2005, 68, 1254-1270. 
https://doi.org/10.1124/mol.105.015669

15. Ratouis, R.; Boissier, J. R.; Dumont, C. J. Med. Chem. 1965, 8, 271-273. https://doi.org/10.1021/jm00326a035

This paper is an open access article distributed under the terms of the Creative Commons Attribution (CC BY) license (http://creativecommons.org/licenses/by/4.0/) 